\title{
Evaluation of X-Band Dual-Polarization Radar-Rainfall Estimates from OLYMPEX
}

\author{
YAGMUR DERIN AND EMMANOUIL ANAGNOSTOU \\ Department of Civil and Environmental Engineering, University of Connecticut, Storrs, Connecticut \\ MARIOS ANAGNOSTOU \\ Institute of Environmental Research and Sustainable Development, National Observatory of Athens, Athens, \\ and Department of Environmental Sciences, Ionian University, Zakynthos, Greece \\ JOHN KALOGIROS \\ Institute of Environmental Research and Sustainable Development, National Observatory \\ of Athens, Athens, Greece
}

(Manuscript received 29 April 2019, in final form 28 June 2019)

\begin{abstract}
The difficulty of representing high rainfall variability over mountainous areas using ground-based sensors is an open problem in hydrometeorology. Observations from locally deployed dual-polarization X-band radar have the advantage of providing multiparameter measurements near ground that carry significant information useful for estimating drop size distribution (DSD) and surface rainfall rate. Although these measurements are at fine spatiotemporal scale and are less inhibited by complex topography than operational radar network observations, uncertainties in their estimates necessitate error characterization based upon in situ measurements. During November 2015-February 2016, a dual-polarized Doppler on Wheels (DOW) X-band radar was deployed on the Olympic Peninsula of Washington State as part of NASA's Olympic Mountain Experiment (OLYMPEX). In this study, rain gauges and disdrometers from a dense network positioned within $40 \mathrm{~km}$ of DOW are used to evaluate the self-consistency and accuracy of the attenuation and brightband/vertical profile corrections, and rain microphysics estimation by SCOP-ME, an algorithm that uses optimal parameterization and best-fitted functions of specific attenuation coefficients and DSD parameters with radar polarimetric measurements. In addition, the SCOP-ME precipitation microphysical retrievals of median volume diameter $D_{0}$ and normalized intercept parameter $N_{W}$ are evaluated against corresponding parameters derived from the in situ disdrometer spectra observations.
\end{abstract}

\section{Introduction}

To understand and manage water systems under a changing climate and meet increasing demand for water, a quantitative understanding of the precipitation variability at a regional to global scale is important. Over complex terrain, in particular, extreme precipitation is the main trigger of natural hazards like floods, landslides, and avalanches and its variability would affect freshwater security, energy, and tourism activities. Nevertheless, the measurement of precipitation over these regions has been very difficult; hence, advancing

\footnotetext{
Corresponding author: Emmanouil Anagnostou, manos@uconn. edu
}

estimation of global precipitation over complex terrain is vitally important for the society.

Rainfall measurements are available from groundbased observations (such as rain gauge and radar networks) and in recent years from satellite sensors. While rain gauges provide direct physical measurement of surface rainfall, the sparseness of gauge networks over mountainous regions limits spatial representation of rainfall variability from these measurements. The difficulty of representing spatial rainfall variability from ground-based observations highlights the need to use multisatellite precipitation datasets-that is, datasets that combine infrared (IR) radiances and passive microwave (PMW) precipitation retrievals-which can represent the space-time variability of rainfall with 
quasi-global coverage (Huffman et al. 2007, 2010; Joyce et al. 2004; Kubota et al. 2007; Ushio et al. 2009). However, the effective use of satellite-based precipitation products requires a thorough understanding of the error characteristics of the individual PMW sensor retrievals at their native resolution. Evaluation of the satellite sensor retrievals at such high spatiotemporal scale cannot be based on rain gauges, since rain gauge measurements are constrained by mismatch in spatial scale with the PMW field of view area. Ground radar observations, on the other hand, provide high-resolution information on the spatial and temporal variability of precipitation. However, radar quantitative precipitation estimation (QPE) accuracy over complex terrain is affected by beam blockage when the radar is close to a mountain range or by the height of the beam and the width of the sampling volume when the radar is far away. To overcome these limitations, locally deployed lowpower polarimetric $\mathrm{X}$-band radars are used to fill gaps in radar networks (Maki et al. 2010).

The use of locally deployed X-band polarimetric radars has many advantages compared to operational $\mathrm{S}$ and $\mathrm{C}$ band radars. Although the range of low-power $\mathrm{X}$-band radar systems is relatively short, their small size, mobility, higher spatial and temporal resolution, and stronger differential phase signals make them a convenient tool for hydrometeorological studies over complex terrain or regions that lack adequate coverage by the operational weather radar networks (Brotzge et al. 2006; Matrosov et al. 2005). Moreover, short-wavelength radars can monitor rainfall variability at smaller scales and are potentially more accurate than the longerwavelength radars (Anagnostou et al. 2009, 2010, 2018; Koffi et al. 2014; Maki et al. 2010; Matrosov et al. 1999, 2013; McLaughlin et al. 2009; Yoshikawa et al. 2010; Wang and Chandrasekar 2010). As with any highresolution reference dataset, X-band polarimetric radar observations require comprehensive evaluation to demonstrate they can be reliably used for evaluation purposes where you consider ground radar as ground truth.

The attenuation of the radar signal at X-band is significantly stronger than $\mathrm{S}$ and $\mathrm{C}$ bands hence these radars are unreliable unless they have polarimetric capabilities. The introduction of polarimetric methods (in particular differential phase shift $\phi_{\mathrm{DP}}$ in degrees) has solved the problem of limited QPE from X-band radars due to power signal attenuation (Kim et al. 2008, 2010; Matrosov et al. 1999, 2002, 2006; Park et al. 2005a,b; Anagnostou et al. 2004; Testud et al. 2000). The immunity of $\phi_{\mathrm{DP}}$ to attenuation from rainfall, or other atmospheric sources, and its independence to radar calibration, make QPE using $\phi_{\mathrm{DP}}$ a powerful method
(E. N. Anagnostou et al. 2006; M. N. Anagnostou et al. 2006; Bringi and Chandrasekar 2001; Chandrasekar et al. 1990; Matrosov et al. 2002, 2005; Testud et al. 2000). Recent studies by Anagnostou et al. $(2009,2010)$ and Kalogiros et al. (2013a) have led to the development and demonstration of a new algorithm for attenuation correction and rain rate and rain drop size distribution parameter estimation that is based on dual-polarization measurements. Kalogiros et al. (2013a,b) showed that their algorithm, which is the self-consistent with optimal parameterization attenuation correction and rain microphysics estimation (SCOP-ME), can provide improved estimates of rain rate and drop size distribution (DSD) parameters. In light of all these advances and advantages, X-band radars and algorithms can play a significant role in the validation of satellite rainfall products (Derin et al. 2018; Chandrasekar et al. 2008).

Over the past two decades, tests and validations conducted with locally deployed X-band radars during field campaigns have shown the effectiveness of these measurements for rainfall parameter retrievals at high temporal and spatial resolutions (Matrosov et al. 2002, 2005; Anagnostou et al. 2004, 2007, 2010, 2018; Houze et al. 2017; Barros et al. 2014; Chandrasekar et al. 2012; Kim and Maki 2012; Chen et al. 2017; Shi et al. 2018; Mishra et al. 2016; Testud et al. 2007; Thurai et al. 2017). A recent ground validation field campaign - the Olympic Mountains Experiment (OLYMPEX)—was carried out to obtain an understanding of orographic modification of frontal precipitation processes and to satisfy the need for further development and refinement of algorithms used to convert Global Precipitation Measurement (GPM) mission satellite measurements to precipitation amounts in midlatitudes. The OLYMPEX campaign involved a wide variety of ground instrumentation, including three state-of-the-art scanning dual-polarization Doppler radars: the NASA dualpolarization S-band radar (NPOL) and the NASA dual-frequency $(\mathrm{Ku} / \mathrm{Ka}$ band) dual-polarization Doppler (D3R) radar, both located near the coast, and the National Science Foundation (NSF) X-band Doppler on Wheels (DOW) radar (Petersen et al. 2018). Because of its blockage by terrain, the NPOL beam did not sample the valley at low levels. The DOW X-band radar was deployed within the valley to fill the gap and extend the dual-polarization radar coverage below the NPOL beam, down nearly to the valley ground level (Houze et al. 2017).

To the best of our knowledge, evaluation of DOW radar rainfall measurements from the OLYMPEX campaign have not yet been carried out, and generally, very few studies (Yu et al. 2018; Lim et al. 2013; Anagnostou et al. 2009, 2010) address the verification 


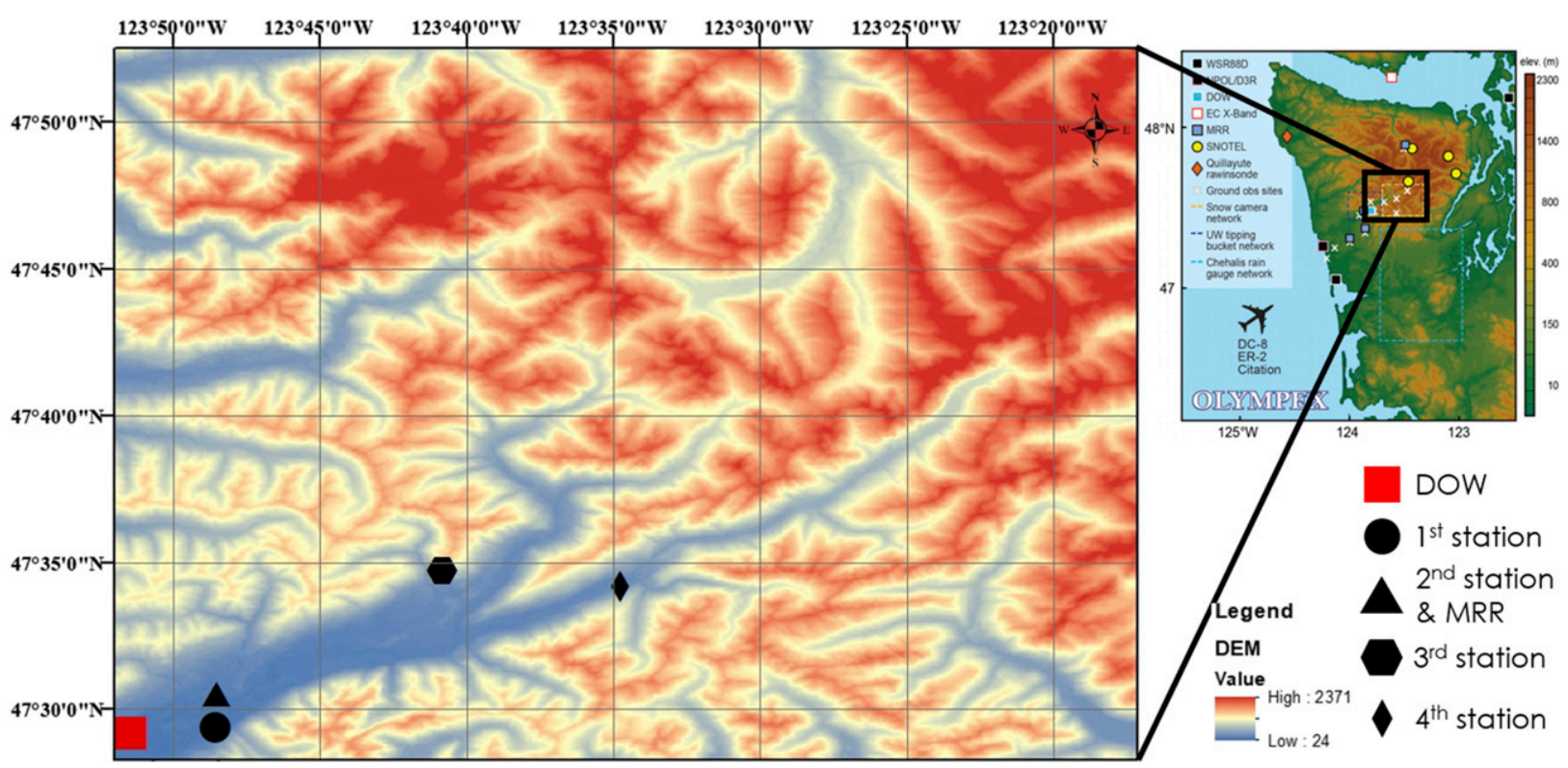

FIG. 1. Topographic map of the study region—-the OLYMPEX campaign. The solid circles on the map represent in situ collocated gauges and APU disdrometers.

of X-band dual-polarization rainfall retrievals in complex terrain. This study presents the microphysical retrieval application on the DOW measurements-the SCOP-ME algorithm - and evaluation of rainfall and microphysical parameters against in situ observations from disdrometers, rain gauges, and a micro rain radar (MRR) available within 30-km range from the radar. The aim of this study is to quantify the error of the SCOP-ME retrieval applied on the DOW measurements, so that these data are properly applied in validation studies of PMW precipitation estimates over this complex terrain.

The paper is organized as follows: section 2 provides the details of the study region and datasets, while the evaluation methodology is presented in section 3 . The results are discussed in section 4 , and section 5 provides a discussion and section 6 summarizes our conclusions and offers recommendations for future research directions.

\section{Study region and datasets}

\section{a. Study region}

The GPM Ground Validation field campaigns have used a variety of methods to validate satellite constellation measurements with surface rainfall measured by dense rain gauge and disdrometer networks at various sites. One such campaign was OLYMPEX, which was conducted in the Pacific Northwest. The goal of OLYMPEX was to validate rain and snow measurements in midlatitude frontal systems as they moved from ocean to coast to mountains and determine how remotely sensed measurements of precipitation by GPM could be applied to a range of hydrological, weather forecasting, and climate data. The campaign involved a wide variety of ground instrumentation, including several radars, and airborne instrumentation monitoring oceanic storm systems as they approached and traversed the Peninsula and the Olympic Mountains.

Figure 1 shows the terrain of the Olympic mountain range, which occupies the Olympic Peninsula of Washington State. The peninsula has a north-south coastline on the Pacific Ocean and is separated from Canada's Vancouver Island on its north side by the narrow Strait of Juan de Fuca.

\section{b. Datasets}

All the datasets that are used in this study were downloaded from Global Hydrology Resource Center (GHRC) Distributed Active Archive Center (DAAC). These data are summarized below.

The DOW radar was deployed in the Chehalis Valley $\left(47.48^{\circ} \mathrm{N}, 123.86^{\circ} \mathrm{W}\right.$; Fig. 1$)$ on the shore of Lake Quinault, Washington, to obtain radar observations of rainfall; the goal was to gain a better understanding of the orographic enhancement of rainfall during frontal passages over mountain ranges. The DOW, which is a mobile dual-polarization and dual-frequency X-band radar, was operated by the Center for Severe Weather Research (CSWR). Rapidly deployable, it has dual 
TABLE 1. DOW and MRR properties.

\begin{tabular}{lcccccc}
\hline \hline Radar & Location & Frequency & Elevation $(\mathrm{m})$ & Beamwidth $\left(^{\circ}\right)$ & Range $(\mathrm{km})$ & Scanning mode \\
\hline DOW & Lake Quinault & X band & 75 & 0.95 & 59.96 & $\begin{array}{l}\text { RHI sectors up-valley interspersed with } \\
\text { low-level PPIs } \\
\text { Vertically pointing }\end{array}$ \\
MRR & Bishop Field & K band & 87 & 2.0 & & \\
\hline
\end{tabular}

250-kW transmitters for high sensitivity to clear radar returns and can be set in place for long-term monitoring of storm systems. The X-band, $3.2-\mathrm{cm}$ wavelength, 9.4-GHz transmissions can penetrate through intense precipitation conditions and return moderately high-resolution horizontal and vertical polarization reflectivity at an operational range of nearly $60 \mathrm{~km}$ (Houze et al. 2017). Both RHI and sector PPI measurements were conducted during OLYMPEX. RHIs contained scans at 22 different azimuths, between $50.4^{\circ}$ and $71.4^{\circ}$. Sector PPIs contained scans at six elevations between $2.8^{\circ}$ and $11.0^{\circ}$ (approximately $2.8^{\circ}, 3^{\circ}, 5^{\circ}, 7^{\circ}, 9^{\circ}$, and $11^{\circ}$ ). Additional information regarding the instrument characteristics and their properties can be found in Tables 1 and 2. Four in situ stations were within the sampling area of DOW. It should be noted that version 2 DOW data have been created after discovering the discrepancy between DOW and NPOL. A new and more appropriate calibration method has been applied (Houze et al. 2018), and in this study DOW version 2 has been used, which was downloaded from GHRC DAAC.

The MRR used in this study, is a Biral/Metek 24-GHz ( $\mathrm{K}$ band), vertically pointing, frequency-modulated continuous-wave (FM-CW) radar. MRR measures the signal backscatter from which Doppler spectra, radar reflectivity, Doppler velocity, and rainfall parameters including drop size distribution, rain rate, liquid water content, and rain-path-integrated attenuation are derived (Petersen and Gatlin 2017). To be able to compare MRR with DOW scans, volumetric matching methodology has been applied by a weighted mean estimator, with the weighting function given by the antenna pattern at $6 \mathrm{~dB}$.

The Met One Rain Gauge Pairs are tipping-bucket precipitation gauges that collect precipitation amounts and calculate rain rates (Petersen et al. 2017a). The
Model 380 series precipitation gauge is a tipping-bucket rain gauge that measures the amount of fallen precipitation. The gauge has a $30.5-\mathrm{cm}$ (12 in.) diameter catchment funnel that directs precipitation to a tippingbucket assembly. When $0.254 \mathrm{~mm}$ of precipitation has been collected, the assembly tips, draining the collection and activating a mercury switch for recording data. Two gauges were located on each platform. Quasicontinuous time series of minutely (1-min) rain rate with a unit of millimeters per hour $\left(\mathrm{mm} \mathrm{h}^{-1}\right)$ were downloaded from GHRC DAAC, in which a cubicspline algorithm was used to interpolate the measured gauge data (Petersen et al. 2017a).

The Autonomous Parsivel Unit (APU) is an optical laser disdrometer based on single particle extinction that measures particle size and fall velocity. The precipitation data provided by the resulting APU dataset include precipitation rate, reflectivity in Rayleigh regime, liquid water content, mean drop diameter, and drop concentration (Petersen et al. 2017b), which can be downloaded from GHRC DAAC. Four APU sites were located within the DOW field of view; their properties are shown in Table 2. All four in situ sites had collocated gauge and disdrometer instruments, and one of the four had the MRR instrument.

\section{c. X-band radar rainfall estimation algorithm}

This section describes the microphysical algorithm (named SCOP-ME; Kalogiros et al. 2013a) that was applied to the DOW X-band radar observations. The SCOP-ME polarimetric rainfall and microphysics algorithm was developed from $\mathrm{T}$-matrix simulations at $\mathrm{X}$ band, based on Rayleigh scattering limit relations, with the addition of a rational polynomial dependence on reflectivity-weighted droplet diameter $D_{Z}$ due to Mie scattering effects. The algorithm is based on the

TABLE 2. In situ stations and instrument properties.

\begin{tabular}{|c|c|c|c|c|c|c|c|}
\hline & \multirow[b]{2}{*}{$\begin{array}{l}\text { Range from } \\
\text { DOW (km) }\end{array}$} & \multicolumn{3}{|c|}{ Beam height $(\mathrm{m})$} & \multicolumn{3}{|c|}{ Instruments } \\
\hline & & Low angles & High angles & Station elevation & $\begin{array}{c}\text { APU } \\
\text { disdrometer }\end{array}$ & MRR & $\begin{array}{c}\text { Dual (D) or } \\
\text { single (S) rain gauge }\end{array}$ \\
\hline 1st station & 4.65 & 302,304 & $613,905,925$ & 64.9 & $\mathrm{x}$ & & $\mathrm{D}$ \\
\hline 2nd station & 5.34 & 320,340 & $703,882,1058$ & 86.9 & $\mathrm{x}$ & $\mathrm{x}$ & $\mathrm{D}$ \\
\hline 3rd station & 14 & 830,875 & $1934,2460,3022$ & 115.8 & $\mathrm{x}$ & & $\mathrm{S}$ \\
\hline 4th station & 23 & 2240,2380 & $5320,6830,8330$ & 180.8 & $\mathrm{x}$ & & $\mathrm{S}$ \\
\hline
\end{tabular}


assumption that a gamma distribution model could adequately describe the shape of drop size distribution. SCOP-ME is a self-consistent polarimetric algorithm, based on the parameterizations of the specific attenuation coefficients and backscattering phase shift in the rain, derived by Kalogiros et al. (2013a), and applied with an iterative scheme to each radar ray. Attenuation correction based on SCOP-ME parameterization of specific attenuation coefficients is applied with an iterative scheme to separate radar rays (Kalogiros et al. 2014). This attenuation correction procedure has been evaluated against in situ disdrometers and rain gauge datasets in past studies (Kalogiros et al. 2013a,b, 2014) and has shown that the it is more efficient than previous polarimetric attenuation correction algorithms (Testud et al. 2000; Gorgucci et al. 2006). Before applying this precipitation retrieval algorithm, the DOW reflectivity observations were corrected for partial beam blockage and measurement biases. For beam blockage estimation high-resolution terrain information and a threedimensional model of the radar beam was applied. This information is used to exclude highly occluded areas from further processing, or to correct reflectivity from areas with occlusion below $50 \%$. In addition, after the application of the attenuation correction and the vertical profile of reflectivity (VPR) measurements, the rainfall estimates in PPI scans were corrected using the method described in Kalogiros et al. (2014). This method is based on the detection of the melting layer using the copolar correlation coefficient measurement, which presents a characteristic minimum in that layer, and an estimate of the scan average of a properly scaled apparent vertical profile without the use of climatological or local radiosonde information. It is noted that the attenuation correction is applied only to heights below the melting layer, while in and above the melting layer it is kept constant in each ray. A summary of the SCOP-ME algorithm is provided in the appendix.

It is stated in Houze et al. (2018) that DOW version 2 data have undergone vigorous quality control. They found an offset in the measured differential reflectivity distribution due to inconsistencies in the transmitters. The offset values were determined by creating histograms of measured differential reflectivity for each scan while omitting values based on known inconsistencies in the transmitters. The values that were omitted based on known inconsistencies are measured differential reflectivity values with an equivalent reflectivity factor from the horizontal channel lower than $10 \mathrm{~dB} Z$, measured differential reflectivity values with a correlation coefficient between the horizontal and vertical channels less than 0.97 or greater than 1.0, and measured differential reflectivity values which fell within $1.2-2.2 \mathrm{~km}$ of the DOW range. The peak of the normal distribution of the measured differential reflectivity histograms was used as the offset for the scan. Abnormally high or low values were omitted from the dataset. When no offset could be determined, a default offset of $0 \mathrm{~dB}$ was used. As a result, an offset estimate of $3.2( \pm 1) \mathrm{dB}$, with the DOW being too low was found based on this method. This offset of $+3.2 \mathrm{~dB}$ was then added to the version 2 dataset. It has been noted in Houze et al. (2018) that in the error estimate, variations between receiver calibrations were also considered (varying up to $1 \mathrm{~dB}$, but typically less). The caveat to this offset is that it does not necessarily hold in melting levels, where Mie scattering becomes an issue, or values greater than $35 \mathrm{dBZ}$. The offset was still applied in these scenarios, but these caveats are kept in mind when analyzing the SCOP-ME retrieval.

The clutter-filtered and calibrated $Z_{H}, Z_{\mathrm{DR}}, \rho_{\mathrm{HV}}$, and $\phi_{\mathrm{DP}}$ parameters, provided by the DOW version 2 dataset, were passed through our algorithm for further dynamic calibration. The bias calibration of $Z_{H}$ and $Z_{\mathrm{DR}}$ was conducted by comparing these measurements to reference radar parameters determined using scattering (T-matrix) routines applied on the raindrop spectral measurements from the disdrometers deployed in the study area. The lowest available (unoccluded) antenna elevation $\left(2.8^{\circ}\right)$ was used for this comparison since DOW observations at this elevation are closest in altitude to the disdrometers and there is no significant beam blockage or ground clutter affecting its measurements. The mean reflectivity bias determined from this process was insignificant, which verifies the calibration offset adjustment applied in DOW version 2 dataset. This aspect was also confirmed by the internal consistency check of the SCOP-ME algorithm described in detail by Kalogiros et al. (2014). The consistency check compares the differential phase shift $\phi_{\mathrm{DP}}$ (in degrees) derived by the attenuation-corrected horizontal reflectivity to the measured differential phase shift. The adjustment of $Z_{\mathrm{DR}}$ was performed in every radar scan using a dynamic correction method based on an average $Z_{H}-Z_{\mathrm{DR}}$ relation derived from scattering simulations, as explained in Kalogiros et al. (2014).

After rain-path attenuation and VPR correction, the rainfall estimation and microphysical algorithms are applied (Kalogiros et al. 2013a); summary of these equations can be found in the appendix.

It should also be noted here that the DOW X-band radar dataset has known measurement noise. Indeed the measured $Z_{\mathrm{DR}}, \rho_{\mathrm{HV}}$, and $\phi_{\mathrm{DP}}$ were noisy (e.g., $0.6 \mathrm{~dB}$ standard deviation of $Z_{\mathrm{DR}}$ noise, $4^{\circ}$ for $\phi_{\mathrm{DP}}$, and 0.02 for $\left.\rho_{\mathrm{HV}}\right)$, however a moderate filtering with \pm 1 gate and \pm 1 ray reduced the noise significantly. Moreover, for measured KDP values a 2-km window moving linear fit has 
been applied, which makes the results less affected by the noise in the raw data. Finally, only events with significant rainfall that exhibit the highest-quality DOW measurements have been selected for this study, which include the following dates: 7, 12,13, and 17 November 2015; 5, 8, 9, 17, and 18 December 2015; and 12 January 2016.

\section{Evaluation methodology}

The evaluation of the SCOP-ME algorithm was conducted against reference in situ rain gauge, disdrometer, and MRR measurements. Based on the ten rain events mentioned above, coincident DOW is extracted, disdrometer, rain gauge, and MRR observations with significant rain in the path between the radar and the in situ measurements. In the comparison of reflectivities between radar and disdrometer, the radar measurement volume above the disdrometer was used at instantaneous time intervals. The time delay due to raindrops falling from the altitude of the radar sampling volume above the disdrometer to ground level is taken into account in the microphysical algorithm used (Kalogiros et al.2013a). The rainfall measurements are accumulated for 15-min and hourly time intervals for evaluation. Throughout the study, evaluation was divided between the closest (first and second) and farthest (third and fourth) in situ stations and at the lowest $\left(2.8^{\circ}\right.$ and $\left.3.0^{\circ}\right)$ and highest $\left(7.0^{\circ}, 9.0^{\circ}\right.$, and $\left.11.0^{\circ}\right)$ elevation angles.

To investigate the agreement among the different products, quantitative and graphical measures are used. The quantitative statistics include mean relative error (MRE), normalized central root-mean-square error (nCRMSE), and correlation coefficient (CORR). MRE and nCRMSE are defined below:

$$
\begin{aligned}
\text { MRE } & =\frac{\sum(R-D)}{\sum D}, \\
\mathrm{nCRMSE} & =\frac{\sqrt{\frac{1}{M} \sum\left[R-D-\frac{1}{M} \sum(R-D)\right]^{2}}}{\frac{1}{M} \sum D},
\end{aligned}
$$

where $D$ represents disdrometer and rain gauge measurements, $R$ represents radar estimates, and $M$ represents the sample size (number of coincident data). The MRE is an error metric measuring the systematic error component with values greater or smaller than zero indicating over or underestimation, respectively, nCRMSE measures the random component of error, as bias has been removed. Correlation coefficient indicates the temporal similarity among rain gauge, disdrometer, and the DOW estimates.
To evaluate the performance of the SCOP-ME attenuation correction algorithm, first, the rain-path attenuation and VPR corrected horizontal polarization $Z_{H}$ (hereinafter referred to as corrected $Z_{H}$ ) reflectivity by the radar to the reflectivity calculated based on the T-matrix simulations of the observed raindrop spectra by the disdrometers are compared. Comparison is performed through scatterplots and by calculating the above statistical metrics (CORR and MRE). At one in situ station collocated MRR and disdrometer $Z_{H}$ data were used to make inferences in between the variability between disdrometer and collocated MRR versus the faraway DOW corrected $Z_{H}$ measurements. Next, to evaluate the performance of the attenuation correction, error statistics of the reflectivity measurements are provided by conditioning relative to path-integrated attenuation (PIA). PIA is determined by calculating the difference between the reflectivity measured by DOW and that calculated from disdrometer measurements; the PIA ranges are $0.5-2,2-4,4-6$, and $>6 \mathrm{~dB}$.

Next, comparisons of rainfall estimates from SCOP$\mathrm{ME}$ algorithm to measurements from rain gauges and disdrometers are conducted, respectively, by using quantitative and graphical measures at 15-min and hourly time intervals. Error statistics include MRE, CORR, and nCRMSE. As we cannot assume the in situ stations (rain gauges and disdrometers) are error-free, rain gauge rainfall measurements are compared against collocated disdrometer rainfall measurements; the variability of the rainfall measurement difference of the two in situ stations represents the reference uncertainty and provides a baseline for comparing the in situ measurements to the SCOP-ME rainfall estimates. It should be noted that in addition to measurement error, scale mismatch between radar measurements and in situ station observations has been written about extensively in the literature. In space, the in situ stations provide point-wise measurements, meanwhile radar provide an averaged value for each resolution volume which is much larger than the volume representative of the gauge or disdrometer observations. Meanwhile on the temporal sampling, the rain gauges measure cumulative rainfall with the resolution of $0.254 \mathrm{~mm}$ at the ground, the radar measure instantaneous rainfall rate. Keeping these in mind, in order to minimize the impact of scale mismatch, measurements are evaluated at higher spatial and temporal resolutions and closer to the ground. Moreover, the comparisons are conducted only at the locations of rain gauges and disdrometers. Another important note to mention here is the disdrometer measurement limitation at small droplets due to light rain events observed in OLYMPEX campaign. This measurement limitation was clearly observed in $D_{0}$ versus $N_{w}$ 

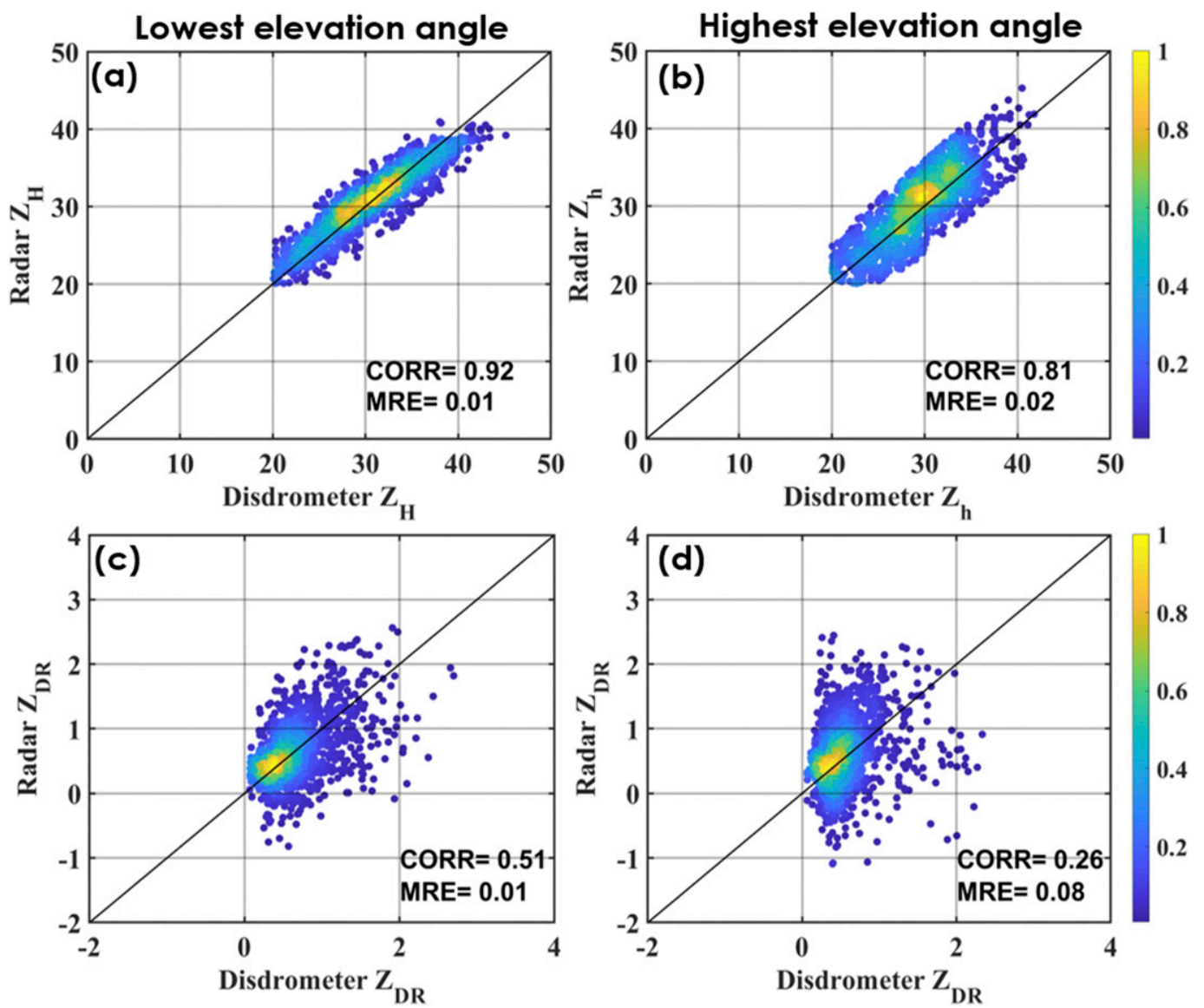

FIG. 2. Attenuation-corrected (a),(b) horizontal reflectivity $Z_{H}$ and (c),(d) differential reflectivity $Z_{\mathrm{DR}}(\mathrm{dB})$ comparison for the (left) lowest elevation angle and (right) highest elevation angle between the disdrometer and DOW for the closest APU disdrometers.

plots. To avoid this limitation, light rainfall events were excluded from the analysis throughout this study.

A comparison of bulk statistics provided by conditioning rainfall magnitudes to three groups (less than 40th quantile, between 40th and 80th quantiles, and greater than 80th quantile) provided insight into the performance of the SCOP-ME rainfall retrieval for different rainfall magnitudes. Moreover, event-based maps provided the spatial distribution of rainfall derived from SCOP-ME algorithm rainfall retrieval. Finally, SCOP-ME algorithm rain microphysics parameters median volume diameter $D_{0}(\mathrm{~mm})$ and intercept parameter $N_{w}\left(\mathrm{~mm}^{-1} \mathrm{~m}^{-3}\right)$ were evaluated by comparing their distribution to corresponding parameters derived from the disdrometer measurements.

\section{Results}

\section{a. Attenuation and VPR correction}

The performance of the SCOP-ME attenuation correction and the VPR correction are evaluated by comparing DOW X-band radar measurements of horizontal reflectivity $Z_{H}$ and differential reflectivity $Z_{\mathrm{DR}}$ to disdrometer-derived $Z_{H}$ and $Z_{\mathrm{DR}}$. Moreover, collocated disdrometer and MRR $Z_{H}$ measurements are evaluated against each other. As mentioned in the previous section, the results are grouped according to elevation angle (lowest and highest) and distance of disdrometers (closest and farthest disdrometers) to the DOW X-band radar location. Finally, bulk statistics are provided comparing DOW X-band radar to disdrometer measurements by conditioning to different PIA values.

Figure 2 shows density scatterplots of the rain-path attenuation and VPR correction and bias adjusted X-band radar horizontal $Z_{H}$ and differential $Z_{\mathrm{DR}}$ reflectivity against corresponding closest disdrometers for the lowest $\left(2.8^{\circ}\right.$ and $3.0^{\circ}$; Figs. $\left.2 \mathrm{a}, \mathrm{c}\right)$ and highest $\left(7^{\circ}, 9^{\circ}\right.$, and $11^{\circ}$; Figs. $\left.2 \mathrm{~b}, \mathrm{~d}\right)$ elevation angles; Table 2 shows the height of each of these bins over each disdrometer. Moreover, the CORR and MRE statistics are reported on each panel. For this analysis $Z_{H}$ values greater than 
$20 \mathrm{dBZ}$ and PIA values less than $6 \mathrm{~dB}$ are considered. Compared to the closest disdrometers attenuation and VPR correction of SCOP-ME algorithm provided almost unbiased results for both $Z_{H}$ and $Z_{\mathrm{DR}}$ for both elevation angles. The correlation coefficient of DOW $\mathrm{X}$-band radar $Z_{H}$ and $Z_{\mathrm{DR}}$ measurements compared to disdrometers for lowest elevation angle are 0.92 and 0.51 , respectively, and the mean relative error values are 0.01 for both measurements. One can argue that the density scatterplots (especially for $Z_{\mathrm{DR}}$ ) look noisy; this could be explained with measurement errors, the difference in height and spatial resolution between the radar volume and the disdrometer. However, the important information here is that the mean relative error is shown to be negligible. Similar scatters have been observed in past studies over complex terrain (Anagnostou et al. 2018, 2009, 2010). CORR of $Z_{H}$ for the highest elevation angle decreased slightly (from 0.92 to 0.81 ) from that for the lowest elevation angle, which is expected due to the inclination angle of the beam and sampling of raindrops at higher altitude in the atmosphere. The highest density for $Z_{\mathrm{DR}}$ measurements of the lowest elevation angle is close to 0 ; however, this high density shifts toward radar $Z_{\mathrm{DR}}$ values of 1 for the highest elevation angle. Again, due to the same reasons, CORR of $Z_{\mathrm{DR}}$ decreased slightly (from 0.51 to 0.26 ) from the lowest to the highest elevation angle.

As mentioned in the previous section, MRR and disdrometer instruments were collocated over one of the in situ locations (Table 2). MRR is a vertically pointing radar, and its reflectivity measurement uncertainty has been reported in past studies. Frech et al. (2017) evaluated the performance of MRR against disdrometer and $\mathrm{C}$-band polarimetric radar. They conclude in their study that the agreement between MRR and radar data is remarkably good considering the spatial and temporal structures of the radar reflectivity. Moreover, they state that the agreement of the reflectivities is very well for values between about 20 and $30 \mathrm{~dB} Z$. They also mention that when the meteorological situation becomes heterogeneous larger differences are observed between MRR and disdrometer. The MRR-disdrometer comparison is conducted to compare the variability of $Z_{H}$ measurements between two collocated instruments to the variability observed in the DOW measurement, which was located $5 \mathrm{~km}$ away from the disdrometer. Figure 3 shows the MRR versus disdrometer $Z_{H}$ measurements plotted as density scatterplot and the associated CORR and MRE statistics. MRR values show a consistent underestimation of disdrometer reflectivity values. One reason for this underestimation could be related to MRR using higher-frequency values that are more severely affected by attenuation than DOW. This

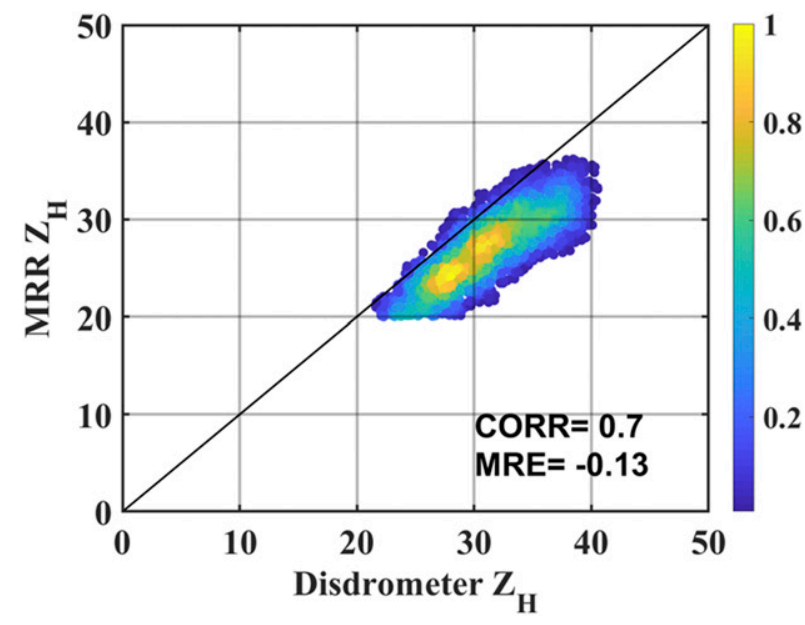

FIG. 3. Horizontal reflectivity $Z_{H}$ comparison between MRR and collocated APU disdrometer.

underestimation is not the subject of the current paper, and we will not be going into detail about the reasons underlying it. It is noted that the variability exhibited in the scatterplot of DOW to disdrometer (Fig. 2) is slightly lower than that of the MRR to disdrometer (Fig. 3), which indicates that the DOW can capture reflectivity from a distance similarly to a collocated MRR instrument. This, once more, qualifies the shortrange DOW reflectivity measurements over complex terrain providing high-resolution spatial and temporal measurements.

Figure 4 provides ray profiles of corrected $Z_{H}$ and $Z_{\mathrm{DR}}$ parameters and the corresponding measurements for the event on 8 December 2015. This profile was taken from DOW's lowest elevation angle ray passing over the third station (Table 2). In Fig. 4 measured values are represented as blue lines and attenuation-corrected or filtered values as red. The horizontal reflectivity corrections by the SCOP-ME algorithm agree significantly with the disdrometer calculation (Fig. 4a), which is located at a distance of about $15 \mathrm{~km}$. With the exception of the spike in Figs. $4 \mathrm{a}$ and $4 \mathrm{~b}$ at a range approximately $13 \mathrm{~km}$ from the radar, the data showed relatively stable $Z_{H}$ and $Z_{\mathrm{DR}}$ especially for attenuation and VPR corrected values. Moreover, in Fig. $4 \mathrm{c}$ is shown to increase at a relatively uniform rate over the pathlength as anticipated especially for filtered values. In moderate rain rates $(\sim 8$-km radar range), where reflectivity is around $35-40 \mathrm{~dB} Z$ for a few kilometers range interval, the differential reflectivity takes on values of about $2 \mathrm{~dB}$, and the slope is in the range of $3.7-4.0 \mathrm{~km}^{-1}$.

These radar parameters measured or estimated in this study are consistent with those of prior experimental studies on X-band polarimetric measurements of rainfall (Anagnostou et al. 2004; Matrosov et al. 2002). 

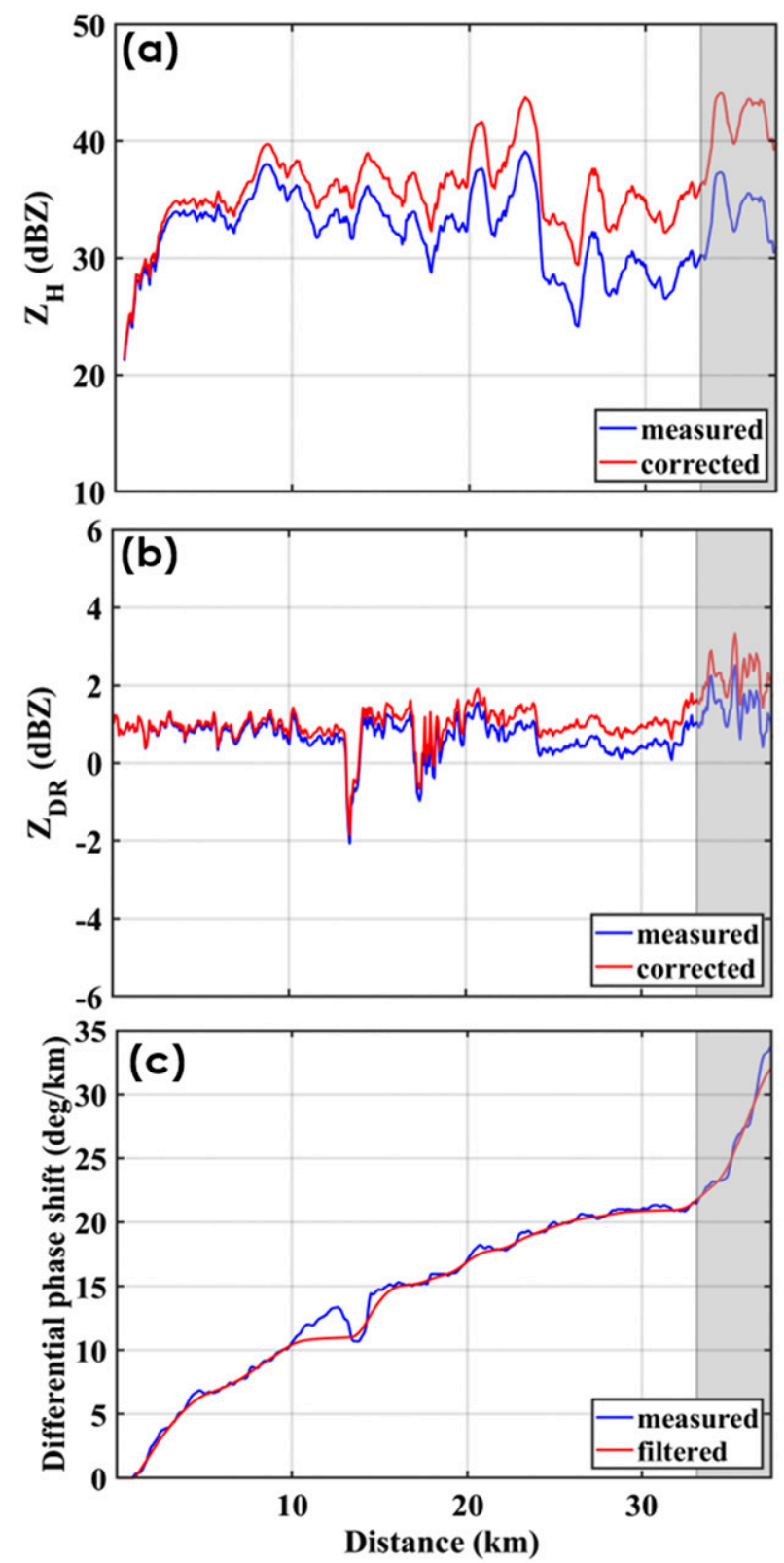

FIG. 4. Ray profiles of measured (blue line) and attenuationcorrected (red line) (a) $Z_{H}$, (b) $Z_{\mathrm{DR}}$, and (c) $\phi_{\mathrm{DP}}$ for the $8 \mathrm{Dec} 2015$ event at 0238 UTC. The gray regions represent the bright band.

Figure 5 shows the bias (difference between radar and disdrometer) and nCRMSE error statistics of $Z_{H}$ (Figs. 5a,b,e,f) and $Z_{\mathrm{DR}}$ (Figs. 5c,d,g,h) for the lowest and highest elevation angles conditioned by PIA, where blue bars represent measured and red bars represent corrected $Z_{H}$ and $Z_{\mathrm{DR}}$ parameters. It should be noted that bias is defined here as the difference of DOW to disdrometer and only $Z_{H}$ values greater than $20 \mathrm{~dB} Z$ are considered. As the figure shows, the corrected $Z_{H}$ measurements had a bias in the range of $\pm 5 \mathrm{~dB}$, and
nCRMSE was around $10 \%$ for all PIA categories for the lowest elevation angle. Most important to note is that the attenuation and VPR correction performances were nearly independent of PIA. For the lowest elevation angle, bias and its variation for measured $Z_{H}$ values increased as PIA increased; meanwhile, bias for corrected $Z_{H}$ remained similar for different PIA ranges except PIA values greater than 6 where the variation of the bias increases however mean bias remained same with other PIA categories. Mean bias for corrected $Z_{H}$ values is almost zero for all PIA categories and for the highest PIA range there is a slight overestimation, while for measured $Z_{H}$ values underestimation in all categories is observed, which is significant underestimation for the highest PIA category. In general, nCRMSE performance of measured and corrected $Z_{H}$ values are very similar to each other and all are smaller than 0.15. Performance for the highest elevation angle differed slightly from that for the lowest. In general, bias increased slightly meanwhile variation increased for both measured and corrected $Z_{H}$ comparisons, as did nCRMSE. The higher variation in bias for the highest PIA category for the highest elevation angles can be explained by beam interception by a bright band. Moreover, attenuation correction brought this high variation in bias to almost unbiased conditions, and, as can be clearly seen from Fig. 5b, correction was stable across the different PIA values except the highest PIA category where the variation remains more or less the same compared to measured variation. It should be noted that the bias for the corrected $Z_{H}$ exhibited slight overestimation for the highest PIA values.

The evaluation for $Z_{\mathrm{DR}}$ showed slightly better results compared to $Z_{H}$ results, bias for both elevation angles were almost zero, with slightly lower variation for all PIA categories. Bias for lowest elevation angle for both measured and corrected $Z_{\mathrm{DR}}$ is almost zero where the variation decreases slightly with increasing PIA categories. Meanwhile, bias for highest elevation angle for both measured and corrected $Z_{\mathrm{DR}}$ is underestimated slightly when the variation of each PIA category is similar to each other. On the other hand, nCRMSE showed dependence on PIA, with slightly higher values at all PIA categories above $0.7 \mathrm{~dB}$. This result is in agreement with findings by Anagnostou et al. (2013) and Kalogiros et al. (2013b). The latter reported that the SCOP-ME algorithm systematically underestimated in cases of strong convective cells associated with large PIA and $Z_{\mathrm{DR}}$ less than $-1 \mathrm{~dB}$ values, due to the presence of mixed-phase hydrometeors in the path of the radar beam.

\section{b. Rain rate retrieval}

In this section, the rainfall retrieval performance of SCOP-ME is evaluated against disdrometers and rain 

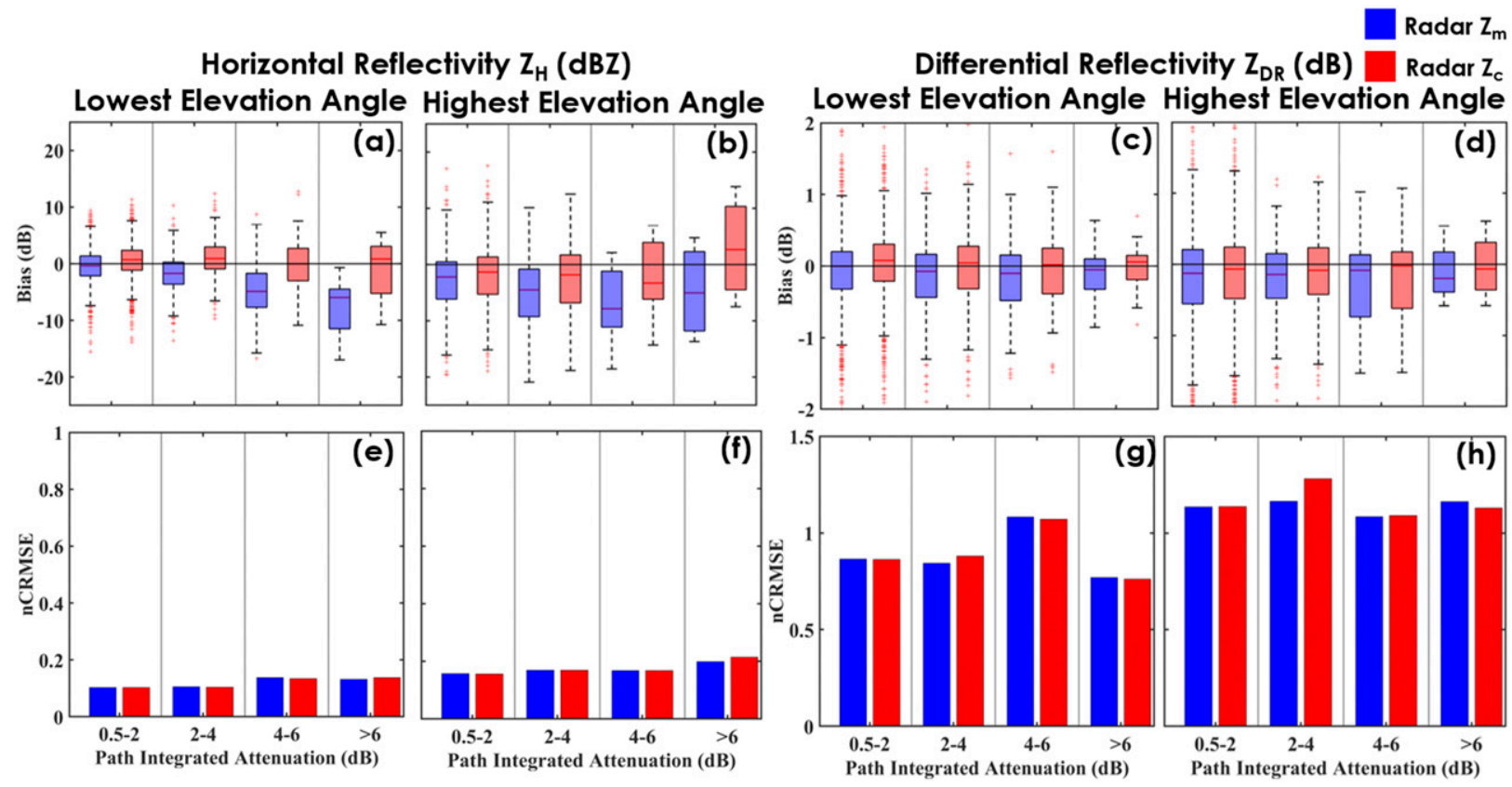

FIG. 5. Bias and nCRMSE bulk error statistics of measured (blue bars) and attenuation-corrected (red bars) (a),(b),(e),(f) horizontal reflectivity $Z_{H}$ and (c),(d),(g),(h) differential reflectivity $Z_{\mathrm{DR}}$ parameters vs PIA. Results are presented for the lowest elevation angles in (a), (c), (e), and (g) and the highest elevation angles in (b), (d), (f), and (h).

gauges for two different temporal resolutions, hourly and $15 \mathrm{~min}$, over the closest and farthest in situ stations. It should be noted here that the rainfall retrieval has been conducted after applying rain-path attenuation and VPR correction to the reflectivity measurements. Hence estimated rainfall at and above the brightband values are adjusted due to the VPR correction. In Fig. 6, the effect of rain-path attenuation and VPR correction on rainfall estimates is shown in an accumulated rainfall map of SCOP-ME retrieval for DOW for one event (8 December 2015). The application of the radar rainfall algorithms over highly complex terrain is very demanding as can be seen from the beam blocked or ground cluttered sectors in this figure. Figure 6a represents the accumulated rainfall values without attenuation and VPR correction, at a longitude higher than $-123.6^{\circ}$ a brightband effect and strong drop behind due to snow return and brightband attenuation effect is observed. Figure $6 \mathrm{~b}$ represents the accumulated rainfall values derived from SCOP-ME after rain-path attenuation and VPR correction was applied to the reflectivity measurements, where the brightband removal and enhancement due to attenuation correction can be observed. The spatial variability of the event was captured well by DOW. At around $-123.5^{\circ}$ longitude and $47.6^{\circ}$ latitude (Fig. 6a) the bright band is observed, when Fig. $6 \mathrm{~b}$ is checked for the same region, the bright band is corrected and the region behind the brightband enhancement of the rainfall due to attenuation correction can be observed.

Figure 7 shows a rainfall comparison of SCOP-ME retrieval at all elevation angles against the closest in situ disdrometers (Figs. 7a,d) and rain gauges (Figs. 7b,e) and of collocated disdrometer versus rain gauge measurements (Figs. 7c,f). The figure provides a density scatterplot and reports corresponding CORR, MRE, and nCRMSE statistics for two different time intervals (hourly and $15 \mathrm{~min}$ ). It should be noted that rainfall values of $0 \mathrm{~mm} \mathrm{~h}^{-1}$ or $0 \mathrm{~mm}(15 \mathrm{~min})^{-1}$ were excluded from the analysis.

Anagnostou and Krajewski (1999) had argued that uncertainty due to measurement error of rain gauge subgrid rainfall variability, can contribute up to $60 \%$ of the random differences observed in radar-rain gauge comparisons. Moreover, the gauge-radar or disdrometerradar differences account for all of the error factors combined and do not provide information about the individual sources of error. To understand the reference measurement uncertainty, in this study the difference of two collocated in situ measurements (rain gauge to disdrometer) is compared to quantify the random component of the rain gauge and disdrometer measurement error.

The nCRMSE for the hourly $(15 \mathrm{~min})$ rain gauge to disdrometer rainfall is $0.4(0.6)$, which is more than $50 \%$ that of the radar versus disdrometer (Fig. 7a) or rain 

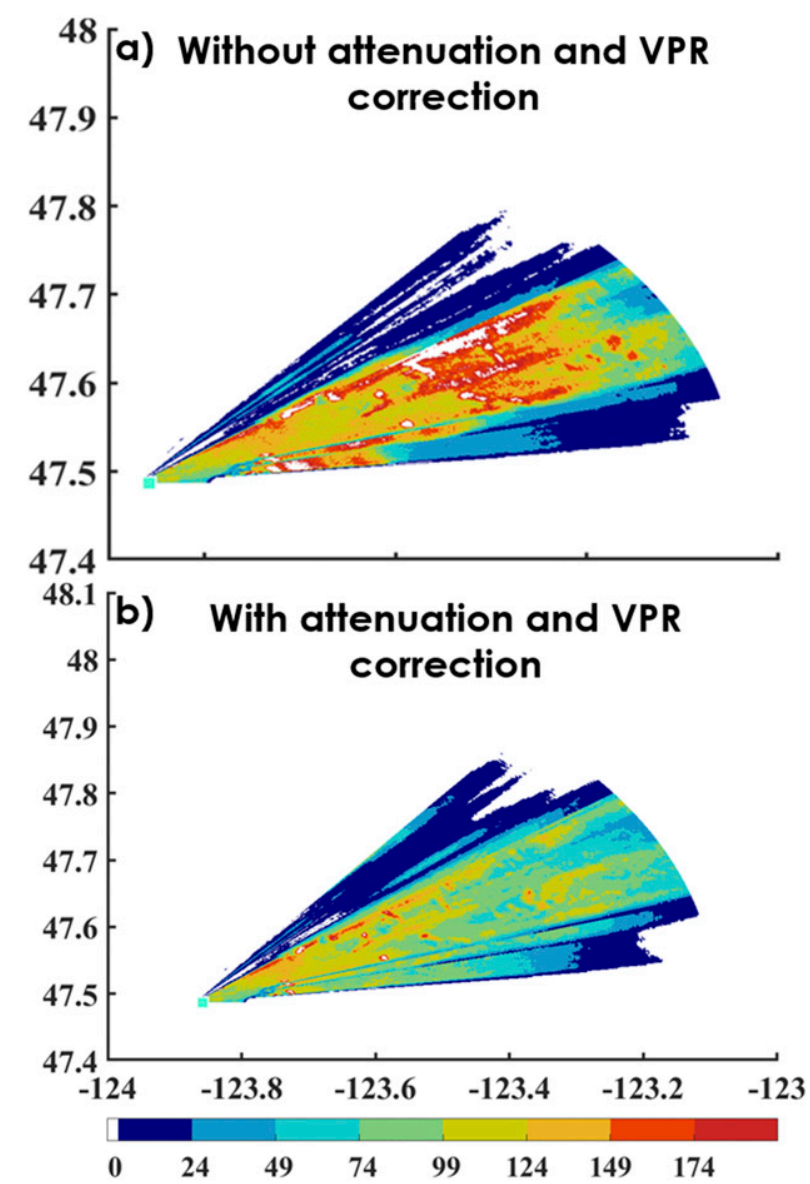

FIG. 6. Color map of accumulated rainfall for 8 Dec 2015 event estimated from DOW (SCOP-ME algorithm) (a) without attenuation correction and (b) with attenuation correction.

gauge (Fig. 7b) comparisons. Keeping this information in mind, further evaluation of the SCOP-ME rainfall retrieval against the rain gauge and disdrometer is conducted. The performances (CORR, MRE and nCRMSE) of the hourly and 15-min rainfall comparisons are very similar to each other. Meanwhile the performance of the radar versus disdrometer and radar versus rain gauge has one significant difference: while radar versus disdrometer reports an MRE value of 0.12 , the radar versus rain gauge reports -0.15 . This difference is explained by the systematic difference observed in the comparison of rain gauge to disdrometer measurements. Other than the systematic error, CORR and nCRMSE values are very similar for the comparisons of SCOP-ME estimates to disdrometer and rain gauge measurements.

Figure 8 presents the bulk statistics of SCOP-ME rainfall retrieval versus disdrometer for the lowest (Figs. 8a,b) and highest (Figs. 8c,d) elevation angles, conditioned by three different reference rainfall magnitude ranges (less than 40th quantile, in between 40th and 80th quantiles, and greater than 80th quantile); the blue (red) bars represent the closest (farthest) in situ stations for 15-min temporal resolutions. Since the statistics were similar to each other for $15-\mathrm{min}$ and hourly rainfall values here only the 15-min rainfall bulk statistics is reported. Figures $8 \mathrm{a}$ and $8 \mathrm{c}$ represent ratio of SCOP-ME rainfall versus corresponding disdrometer rainfall value and Fig. 8b represents nCRMSE values. The solid black line on the nCRMSE plots represents corresponding values calculated from collocated disdrometer to rain gauge rainfall measurements for each quantile interval. The SCOP-ME rainfall retrieval overestimates slightly the lowest rainfall magnitudes meanwhile it shifts to slight underestimation for highest rainfall magnitudes for both closest and farthest disdrometers. The variation of the ratio significantly diminishes as the rainfall magnitudes increase for both the lowest and highest elevation angles. In general, the trend of the ratios is similar when the lowest and highest elevations are compared to each other with the highest elevation angles' mean ratio value being slightly higher than the value of the lowest elevation angles. The nCRMSE values introduced from measurement error (rain gauge versus disdrometer) is more than $70 \%$ for the lowest elevation angles' evaluation. Moreover, the farthest disdrometer's nCRMSE values for each rainfall magnitude is significantly higher than the closest disdrometers. For both the closest and farthest disdrometers, the nCRMSE values are decreasing slightly as the rainfall magnitude is increasing. The nCRMSE values for the highest elevation angles' lowest rainfall magnitude are significantly (1-1.3) higher compared to the lowest elevation angles (0.6-1), while the rest of the rainfall magnitudes are similar to each other.

Last, event-based X-band radar retrieved rainfall is compared against the corresponding closest disdrometer for the lowest elevation angle (Fig. 9). For this comparison bias (difference of radar to disdrometer) and normalized absolute error [absolute error normalized by the reference (disdrometer)] are calculated for each event. Bias (Fig. 9a) varies from -2.5 to 2.5 for the disdrometer comparison. The bias exhibits no overall trend with respect to the event-based radar rainfall for the disdrometer comparison. It should be noted that in monitoring heavy rainfall, radar retrieval should not increase proportionally with the rainfall intensity. Most importantly, the X-band radar retrieval is almost unbiased in the overall sense. The normalized absolute error (Fig. 9b), on the other hand, exhibits an increasing trend with increasing rainfall intensity. These results align very closely with the Wang and Chandrasekar (2010) study where they compared an X-band radar 

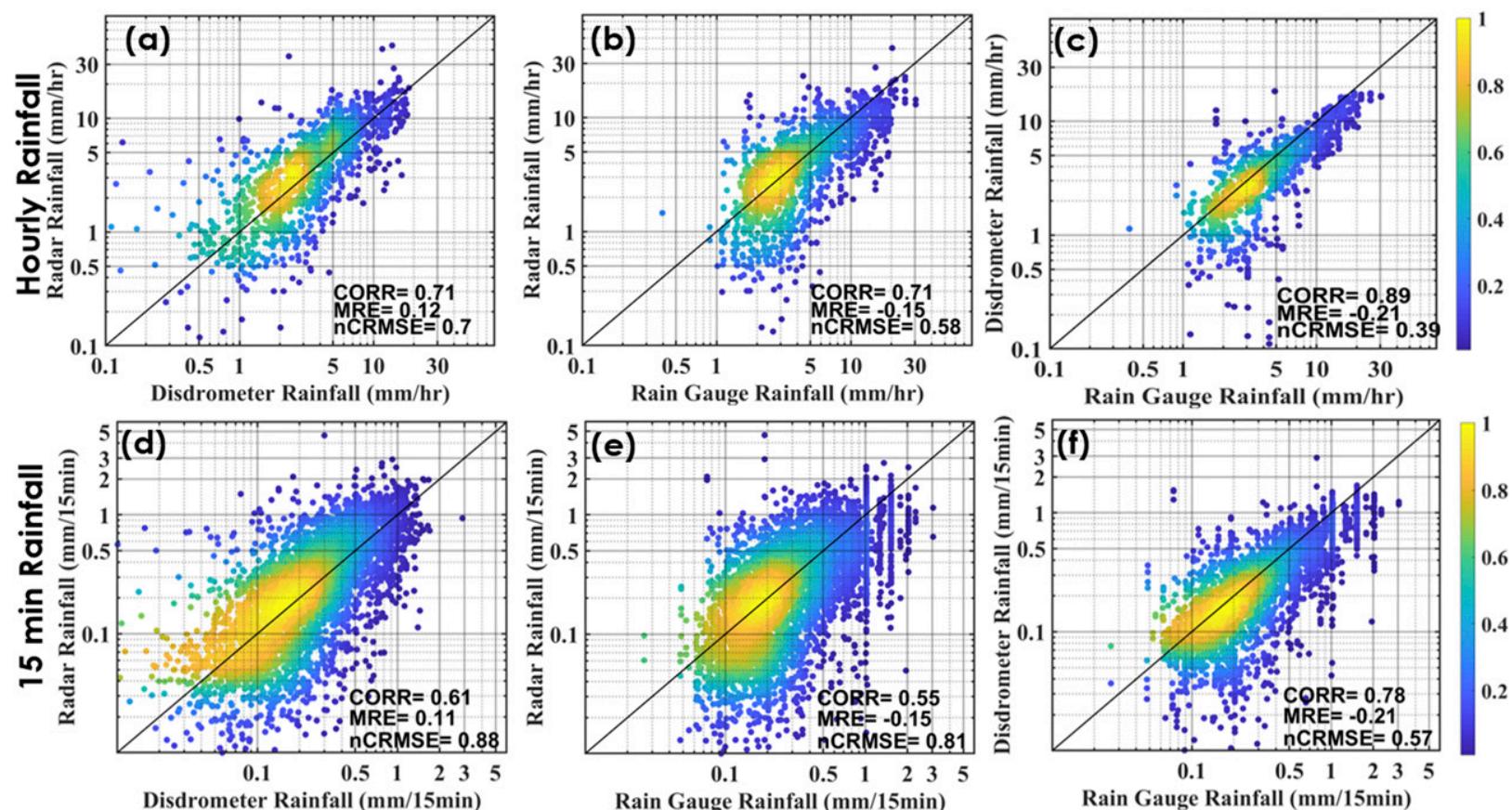

FIG. 7. Density scatterplots of DOW (SCOP-ME retrieval) vs closest in situ (a),(d) APU disdrometers and (b),(e) rain gauges rainfall rates for (top) hourly and (bottom) 15-min temporal resolutions. Density scatterplots of APU disdrometer vs rain gauge rainfall rates for (c) hourly and (f) 15-min temporal resolutions.

network against a rain gauge network over southwest Oklahoma.

\section{c. Rainfall DSD parameters}

In this section the accuracy of the estimation of rainfall DSD-normalized gamma model parameters from DOW observations are investigated. The SCOP-ME algorithm error statistics are evaluated against the two closest and farthest APU disdrometers for all elevation angles. The comparison is conducted only for convective rains where the instantaneous rain rate is greater than $0.2 \mathrm{~mm} \mathrm{~h}^{-1}$. Figure 10 shows the probability distribution plots of the DOW estimates of the two DSDnormalized gamma model parameters $\left(N_{w}\right.$ and $\left.D_{0}\right)$ against parameters derived from disdrometer observed spectra using the DSD moments method (Bringi et al. 2003). SCOP-ME $D_{0}$ estimates of all elevation angles exhibited underestimation values below 0.8 and overestimation values above 0.8 . SCOP-ME $N_{w}$ performance of all elevation angles shows slight underestimation at values less than 3 and above 4.5, meanwhile slight overestimation at values in between 3 and 4.5.

Figure 11 presents the density scatterplots of the two DSD parameters $\left(\log _{10} N_{w}\right.$ versus $\left.D_{0}\right)$ for disdrometer (Fig. 11b) and DOW (Fig. 11a) for all elevation angles. As shown in this figure, DOW SCOP-ME estimates give a negative slope similar to the slope of the APU reference measurements. It is clear from this figure the similarities in terms of size dimensions (on both the radar and disdrometers, the $D_{0}$ ranges between 0.5 and 1.5 and $\log _{10} N_{w}$ between 3.5 and 5) and the average slope of $\log _{10} N_{w}-D_{0}$ relation in the SCOP-ME retrieval and reference parameters. As shown in the figure, the core of the SCOP-ME density is over $D_{0}$ estimates of 1.1-1.2 meanwhile disdrometer estimates are over $0.9-1$. This overestimation is consistently seen in the marginal PDF of $D_{0}$ shown in Fig. 10. These results are in agreement to those presented in Anagnostou et al. (2013) study, which compared the SCOP-ME algorithm to three other algorithms. In that study SCOP-ME $D_{0}$ estimates were slightly overestimating the reference $D_{0}$ estimates and the core of the SCOP-ME density was in the range of 1.3-1.4 while the corresponding disdrometer estimates were between 1.1 and 1.2. This could be due to the generally low rainfall rates and small $D_{0}$ values recorded during the campaign, which may introduce sampling errors in disdrometers or biases due to measurement noise or remaining clutter in radar estimates.

The bulk statistics of the error of the DSD parameters estimated from the SCOP-ME algorithm to those derived from the disdrometer observations can be found in Table 3. Results are presented for all elevation angles and for the closest and farthest disdrometers. There is a 

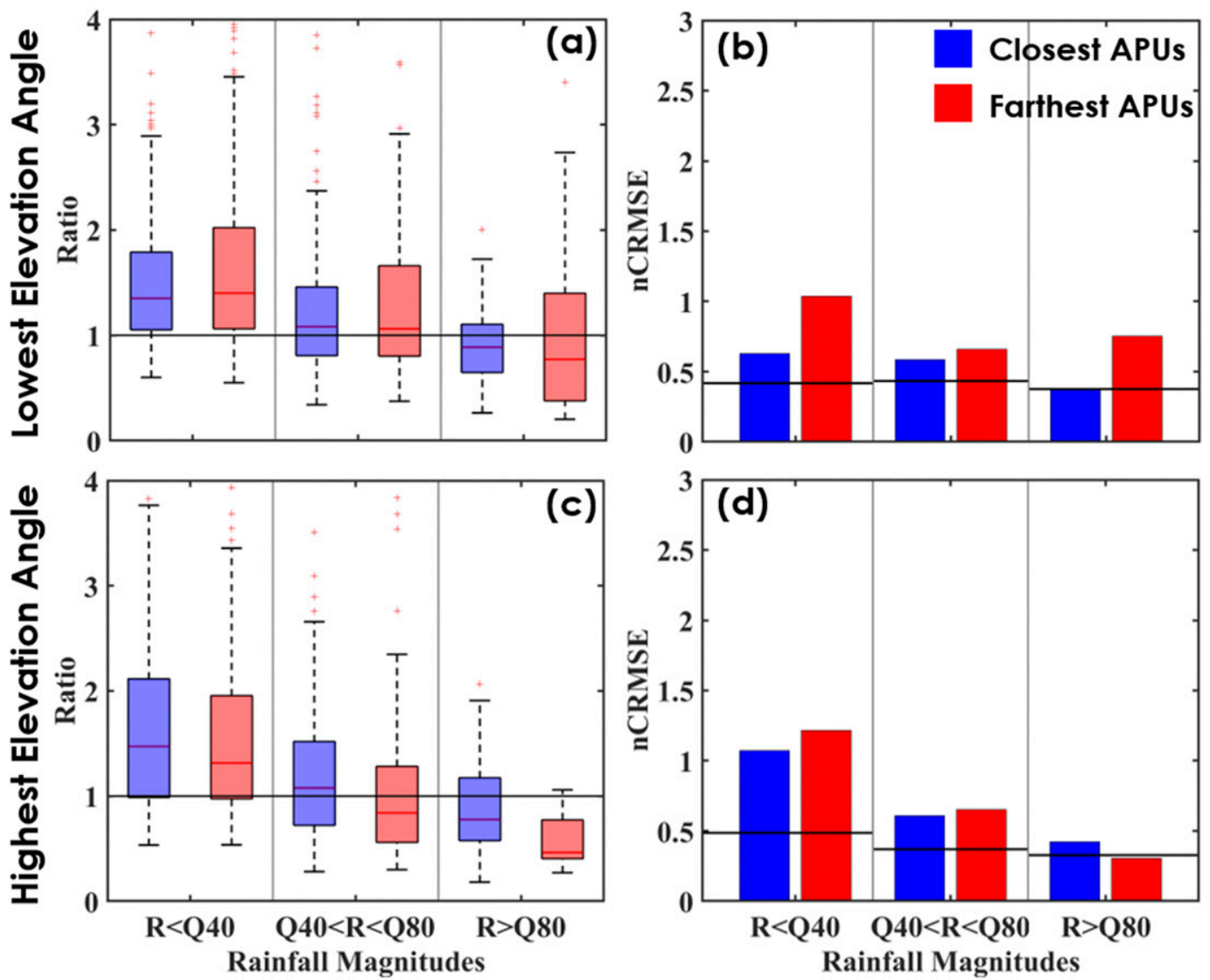

FIG. 8. Bias and nCRMSE bulk statistics of SCOP-ME retrieval error against APU disdrometer derived rain rates vs rainfall magnitude. Results are presented for the (a),(b) lowest and (c),(d) highest elevation angles' 15-min temporal resolution.

slight overestimation of $D_{0}$ values for close disdrometers $($ Bias $=0.03)$ and slight underestimation for farthest disdrometers $\left(\right.$ Bias $=-0.03$ ). The nCRMSE values of $D_{0}$ for the closest and farthest disdrometers exhibited similar performances with 0.16 and 0.1 . The $N_{w}$ showed slightly higher bias values compared to $D_{0}$ especially for the farthest disdrometers. Moreover, the closest disdrometers exhibited slight underestimation (Bias $=-0.05)$, meanwhile, the farthest disdrometers had slight overestimation (Bias $=0.15)$. The nCRMSE values of $N_{w}$ are lower than $D_{0}$ with 0.05 and 0.09 .

\section{Discussion}

To summarize the performance of the rainfall retrieval, mean bias (MB), normalized mean bias (NB), normalized absolute error (NAE), and normalized standard (root-mean-square) error (NSE) were calculated for the radar lowest elevation angle against the closest disdrometer rainfall values. NB is the difference between the mean estimated and reference values normalized to the mean reference value. NSE is the root-mean-square error normalized with respect to the mean reference value. The aforementioned statistics are calculated for a15-min (hourly) time interval over closest disdrometers which are reported as MB of $5.8 \mathrm{~mm}$ $(0.8 \mathrm{~mm}), \mathrm{NB}$ of $14.03 \%(11.5 \%)$, NSE of $68.8 \%$ $(61.3 \%)$, and NAE of $49.1 \%(42.9 \%)$. The farthest disdrometers provided similar statistics. These statistics show an excellent performance of the SCOP-ME rainfall retrieval system for the 10 events examined in this study. These results are encouraging especially when compared to the literature, and qualify the SCOP-ME retrieval as a great data source of high-resolution spatial and temporal precipitation variability in complex terrain. For comparison, we summarize below XPOL rainfall estimation performance results from studies in the literature.

Chandrasekar et al. (2012) evaluated X-band dualpolarization radar retrievals over low terrain for high rainfall magnitudes and concluded that the hourly rainfall estimates compared to gauge measurement have am MB of 3.74 and NAE of $25 \%$. Lim et al. (2013) conducted precipitation quantification using X-band 

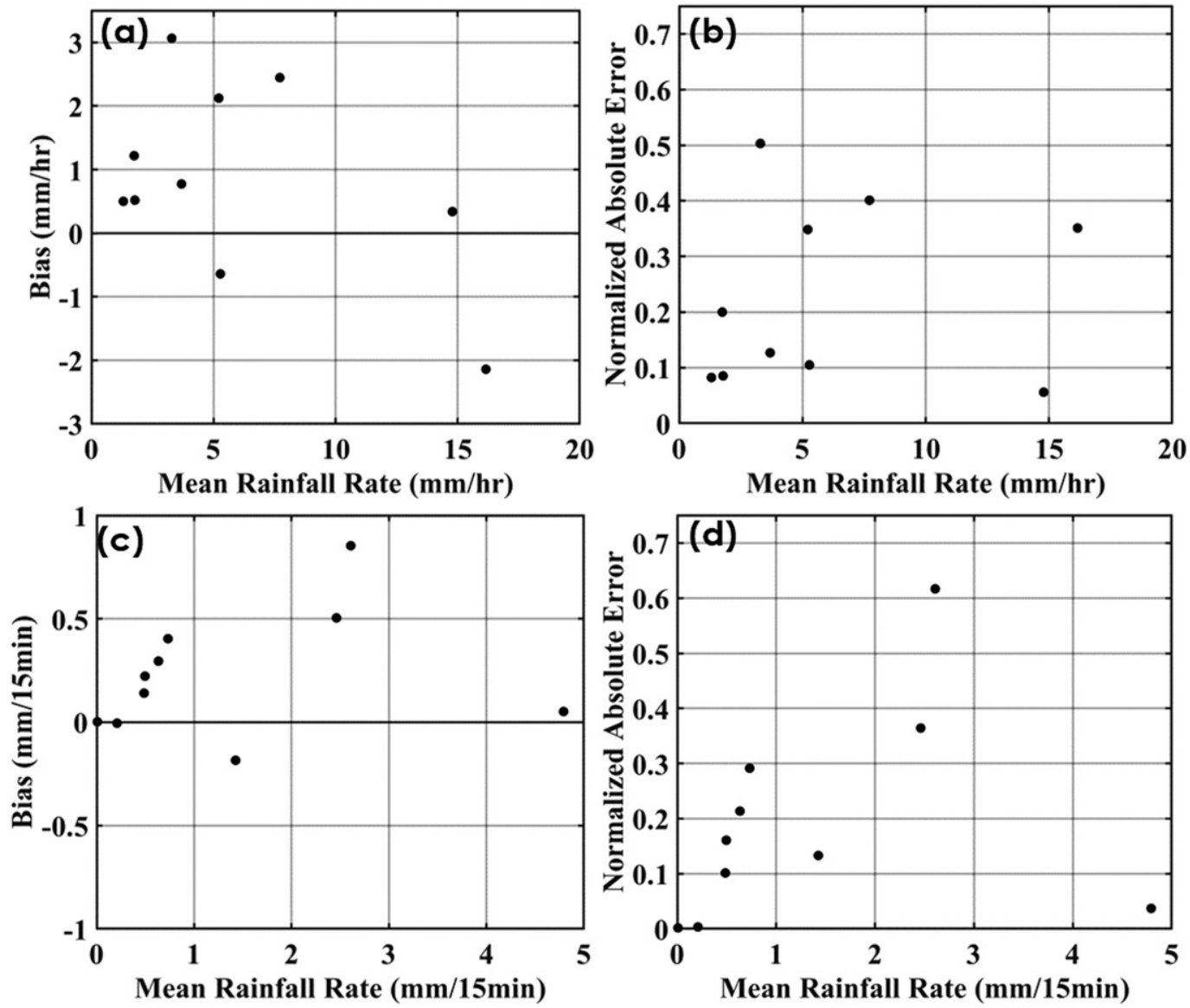

FIG. 9. (left) Event-wise bias and (right) normalized absolute error of SCOPE-ME retrieval vs closest disdrometer rainfall magnitudes for (a),(b) hourly and (c),(d) 15-min rainfall for lowest elevation angle.

dual-polarization radar from Hydrometeorology Testbed in orographic terrain of California against rain gauges. In this study rainfall retrieval was conducted by using the $K_{\mathrm{DP}}$ filtering method and developing a new $K_{\mathrm{DP}}$ method. Instantaneous rainfall comparison was conducted for these two retrieval techniques against rain gauges where $\mathrm{NB}$ is calculated for the $K_{\mathrm{DP}}$ filtering method (new $K_{\mathrm{DP}}$ method) as $-1.24 \%(-0.19 \%)$ and NAE was calculated as $42.41 \%(39.28 \%)$.

Wang and Chandrasekar (2010) conducted a performance evaluation of an X-band dual-polarization radar network over southwestern Oklahoma. Rainfall retrieval was conducted by using an adaptive $K_{\mathrm{DP}}$ estimation. The performance evaluation was conducted against a rain gauge network in which continuous rainfall accumulations from gauge measurements were considered as baseline. The NAE at hourly resolution was $22.76 \%$ and $\mathrm{MB}$ was $4.26 \mathrm{~mm}$.

Shi et al. (2018) conducted a performance evaluation of an X-band dual-polarization radar over Guangdong province, China. In their study they evaluated two different polarimetric rainfall retrievals: $R\left(Z_{H}, Z_{\mathrm{DR}}\right)$ and $R\left(K_{\mathrm{DP}}\right)$. These $\mathrm{X}$-band radar retrievals were compared to in situ rain gauges at hourly time intervals and NB was shown to be $-13.62 \%$ and $-10.65 \%$ for $R\left(Z_{H}, Z_{\mathrm{DR}}\right)$ and $R\left(K_{\mathrm{DP}}\right)$, respectively. They concluded that the difference of the two algorithms is not remarkable, which implies that attenuation and bias correction are critical for X-band radar rainfall retrieval applications.

Anagnostou et al. (2013) evaluated the herein SCOP-ME algorithm against disdrometer rainfall observations and concluded that retrieval has low relative error in all PIA categories where relative error ranged between $10 \%$ underestimation and $1 \%$ overestimation, and relative root-mean-square error was in the range of $0.8-0.9$.

Koffi et al. (2014) evaluated DOW retrievals over low terrain at hourly time scale, and concluded that relative root-mean-square error was below $50 \%$ at rainfall magnitudes below $10 \mathrm{~mm} \mathrm{~h}^{-1}$ and below $30 \%$ above $10 \mathrm{~mm} \mathrm{~h}^{-1}$. Shi et al. (2018) evaluated DOW retrievals over complex terrain and concluded that their hourly 

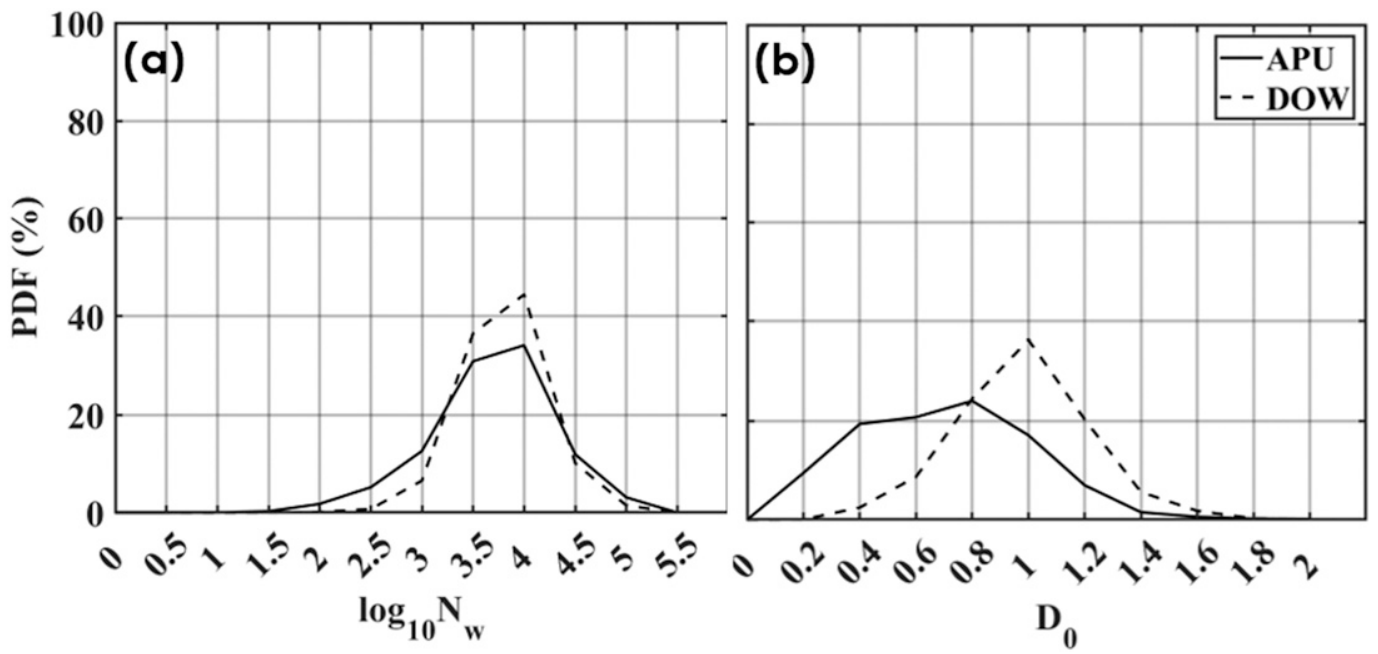

FIG. 10. Probability density functions of (a) $N_{w}$ and (b) $D_{0}$ derived from DOW (SCOP-ME retrieval) and APUs.

rainfall estimates compared to gauge measurements had a normalized mean bias of $-10.65 \%$.

The accuracy of the radar parameters estimated in this study is consistent to prior experimental studies on X-band polarimetric measurements of rainfall (Anagnostou et al. 2004; Anagnostou et al. 2013, 2018; Matrosov et al. 2002; Kalogiros et al. 2013a). The nCRMSE for $Z_{\mathrm{DR}}$ showed dependence on PIA categories, with significantly high values at PIA values above $2 \mathrm{~dB}$. These results are in agreement with those of Anagnostou et al. (2013) and Kalogiros et al. (2013b). In the latter study, the authors reported the SCOP-ME algorithm systematically underestimated in cases of strong convective cells with large PIA and $Z_{\mathrm{DR}}$ at values less than $-1 \mathrm{~dB}$, due to the presence of mixed-phase hydrometeors in the path of the radar beam (Kalogiros et al. 2013b).

\section{Closing remarks}

In this study we applied the SCOP-ME algorithm in the OLYMPEX X-band dual-polarization radar (DOW) observations, and evaluated its performance against in situ observational data collected over complex terrain.

The corrected for rain-path attenuation and VPR $Z_{H}$ measurements exhibited an overall good performance, with low bias compared to collocated disdrometerderived $Z_{H}$ values. The correction of $Z_{H}$ was nearly independent of PIA. The lowest elevation beams
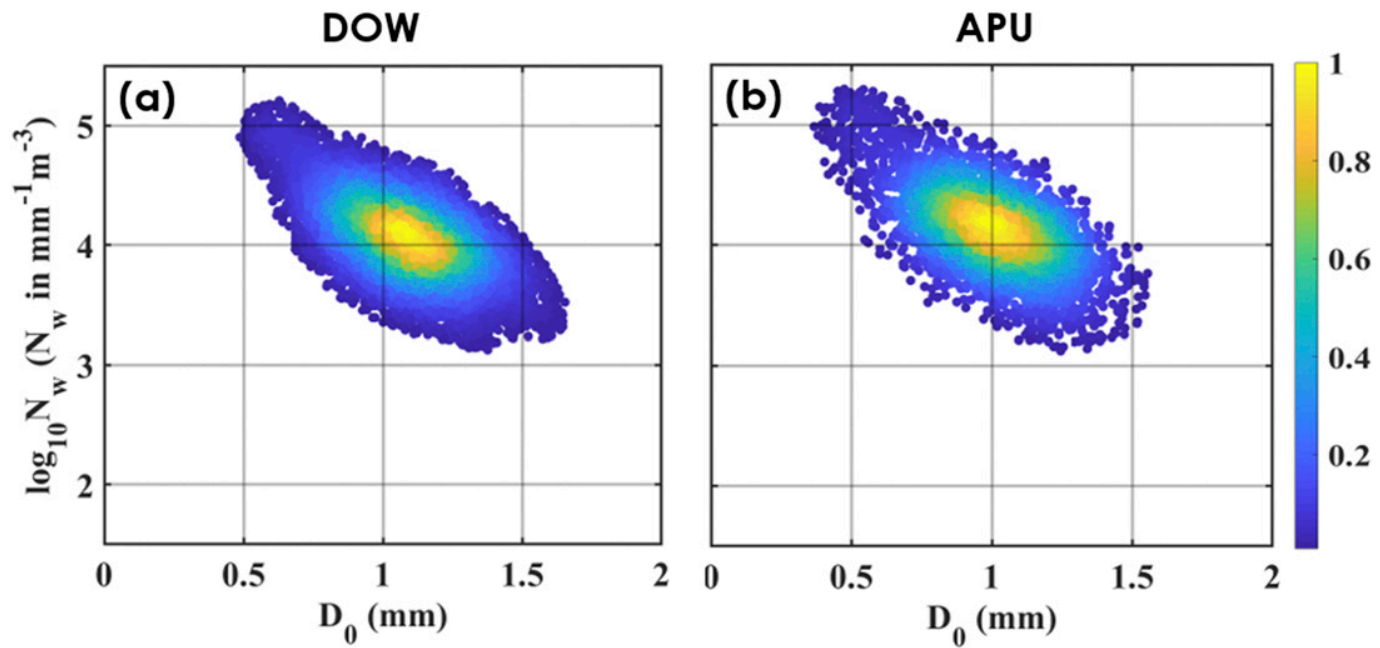

FIG. 11. Density scatterplots of $\log _{10} N_{w}\left(\mathrm{~mm}^{-1} \mathrm{~m}^{-3}\right)$ vs $D_{0}(\mathrm{~mm})$ from (a) DOW (SCOP-ME retrieval) and all elevation angles and (b) APU disdrometers. 
TABLE 3. Bias and nCRMSE bulk error statistics of DOW (SCOP-ME retrieval) estimated $D_{0}(\mathrm{~mm})$ and $N_{w}\left(\mathrm{~mm}^{-1} \mathrm{~mm}^{-3}\right)$. Results are presented separately for the closest and farthest disdrometers.

\begin{tabular}{lcccccc}
\hline \hline & \multicolumn{2}{c}{$D_{0}(\mathrm{~mm})$} & & & \multicolumn{2}{c}{$\begin{array}{l}\log _{10}\left(N_{w}\right) \\
\left(\mathrm{mm}^{-1} \mathrm{~mm}^{-3}\right)\end{array}$} \\
\cline { 2 - 3 } \cline { 6 - 7 } & \multicolumn{2}{c}{ Bias } & nCRMSE & & Bias & nCRMSE \\
\hline Closest disdrometers & 0.07 & 0.16 & & -0.05 & 0.05 \\
Farthest disdrometers & -0.03 & 0.10 & & 0.15 & 0.09 \\
\hline
\end{tabular}

exhibited better performance than beams at higher elevation angles when bulk statistics were checked. Evaluation for $Z_{\mathrm{DR}}$ showed good results in terms of bias, for both elevation angles having almost zero bias with slight lower variation for each PIA category and less PIA dependence.

The error statistics of the SCOP-ME rainfall estimation were based on in situ rain gauges and disdrometer rainfall observations for 15-min and hourly temporal resolutions. The results showed that SCOP-ME has a low bias, especially in higher magnitudes for both temporal resolutions. It is noted that the lowest rainfall magnitudes exhibited the highest mean bias values, so care should be taken when rain rates of these magnitude are used for validation of satellite precipitation datasets. Moreover, the nCRMSE determined from the differences of disdrometers to collocate rain gauges was used to define the reference measurement error variance. Hence, inferences made by comparing reference rainfall nCRMSE to those determined from the radar to disdrometer or radar to rain gauge comparisons are used to understand the random error component of SCOP-ME retrieval.

Last, evaluation of microphysical parameters from the DOW dual-polarization observations was conducted using in situ disdrometer observations. Overall, SCOP-ME estimates of the $D_{0}$ parameter exhibited low bias and performed well for all PIA ranges, meanwhile these had relatively higher nCRMSE values. The $N_{w}$ estimates, exhibited similar bias values with higher variation. Meanwhile nCRMSE values for $N_{w}$ had less dependence on the different PIA categories.

Extension of this work in a future study would include evaluation of the algorithm in additional complex terrain areas to generalize the SCOP-ME performance results. These future studies would include experimental data from multiple regions including the Alps and Andes, and mountainous areas in Arizona, Colorado, and South Korea. The goal is to demonstrate that an algorithm with small parameterization error like SCOP$\mathrm{ME}$ applies to any X-band dual-polarization radar over complex terrain, and its estimators can be considered as a ground truth precipitation product. Eventually these high-resolution precipitation datasets will be used to evaluate more extensively PMW retrievals similar to Derin et al. (2018), which could provide significant information to algorithm developers of global satellite precipitation datasets.

Acknowledgments. This work was supported by the Eversource Energy Center at the University of Connecticut.

\section{APPENDIX}

\section{Summary of the SCOP-ME Algorithm}

\section{a. SCOP-ME algorithm}

The SCOP-ME polarimetric rain microphysics algorithm is based on relationships valid at the theoretical Rayleigh scattering limit, which is corrected by a reflectivity-weighted raindrop diameter $D_{Z}$ [Eq. (A1)] multiplicative rational function to approximate the Mie scattering character at these electromagnetic frequencies

$$
D_{Z}=\frac{E\left[D^{7}\right]}{E\left[D^{6}\right]}
$$

where $D$ is the raindrop equivolume diameter and $E$ stands for the expectation value. The expectation value is estimated in practice as the DSD-weighted integral over the whole range of diameter values.

Kalogiros et al. (2013a) developed the algorithm from T-matrix scattering simulations for a wide range of DSD parameters, a variable raindrop axis ratio around the relationship given by Beard and Chuang (1987), a Fisher distribution with a $7.5^{\circ}$ circular standard deviation for canting angle distribution, and air temperature ranging from $5^{\circ}$ to $20^{\circ} \mathrm{C}$.

The rain drop size distribution model used in the simulations was the normalized gamma distribution $n(D)$, as presented in many polarimetric radar rainfall studies (Testud et al. 2000; Bringi and Chandrasekar 2001; Illingworth and Blackman 2002):

$$
n(D)=N_{w} f(\mu)\left(\frac{D}{D_{0}}\right)^{\mu} \exp \left[-(\mu+3.67) \frac{D}{D_{0}}\right]
$$

where $n(D)\left(\mathrm{m}^{-3} \mathrm{~mm}^{-1}\right)$ is the volume density, $D_{0}(\mathrm{~mm})$ is the median volume diameter, $N_{w}\left(\mathrm{~mm}^{-1} \mathrm{~m}^{-3}\right)$ is the intercept parameter, and $\mu$ (no units) is the shape parameter. The SCOP-ME rainfall rate relation is given by the following equation (Kalogiros et al. 2013a): 


$$
R=0.8106 F_{R}(\mu) N_{w} D_{0}^{4.67} f_{R_{2}}\left(D_{0}\right),
$$

where the factor accounts for an exponential relationship more accurate than the usual power law (Atlas et al. 1973; Bringi and Chandrasekar 2001) and for the terminal velocity of raindrops against their diameter. The median volume diameter $D_{0}$, the intercept parameter $N_{w}$, and the shape parameter $\mu$ of the DSD are estimated from the polarimetric radar measurements $Z_{H}$, $Z_{\mathrm{DR}}$, and $K_{\mathrm{DP}}$ and also the function $F_{R}(\mu)$ by

$$
\begin{aligned}
F_{R}(\mu)= & 0.6 \times 10^{-3} \pi \times 3.78 \frac{6}{3.67^{4}} \frac{(3.67+\mu)^{\mu+4}}{\Gamma(\mu+4)} \\
& \times \frac{\Gamma(\mu+4.67)}{(\mu+3.67)(\mu+4.67)},
\end{aligned}
$$

where $\Gamma$ indicates the gamma function;

$$
\begin{aligned}
D_{0} & =D_{Z} f_{D_{0}}\left(D_{Z}\right), \\
D_{Z} & =D_{Z_{1}} f_{D_{Z_{1}}}\left(D_{Z_{1}}\right), \\
D_{Z_{1}} & =0.1802\left[\frac{Z_{H}}{K_{\mathrm{DP}}} \xi_{\mathrm{DR}}^{-0.2929}\left(1-\xi_{\mathrm{DR}}^{-0.4922}\right)\right]^{1 / 3}, \\
N_{W} & =3610\left(\frac{K_{\mathrm{DP}}}{1-\xi_{\mathrm{DR}}^{-0.3893}}\right) D_{0}^{-4} f_{N_{W_{2}}}\left(D_{Z}\right), \quad \text { and } \\
\mu & =165 e^{-2.56 D_{0}-1,}
\end{aligned}
$$

where $D_{Z}$ is the reflectivity-weighted mean diameter $(\mathrm{mm}), \xi_{\mathrm{DR}}$ is the differential reflectivity in linear units, and the horizontal reflectivity $Z_{H}$ in these relations is also given in linear units $\left(\mathrm{mm}^{6} \mathrm{~mm}^{-3}\right)$. For more information, the reader may see Kalogiros et al. (2013a).

\section{b. Attenuation correction}

Before applying the algorithm $Z_{H}$ and $Z_{\mathrm{DR}}$ reflectivities are corrected for attenuation in rain. The basis of the attenuation correction algorithm is the new parameterizations of $A_{H}$ and $A_{\mathrm{DP}}$ from dualpolarization radar observables $Z_{H}, Z_{\mathrm{DR}}$, and $K_{\mathrm{DP}}$ in rain, which were found from T-matrix scattering simulations at $\mathrm{X}$ band $(9.37 \mathrm{GHz})$, carried out for a very wide range of values of rain DSD and drop shape parameters, air temperature, and an elevation of the radar antenna close to zero (Kalogiros et al. 2014).

\section{c. VPR correction}

Reflectivity measurements and rainfall estimates in plan position indicator (PPI) scans of polarimetric weather radars in the melting layer (bright band) and the snow layer above it are corrected for the vertical profile of reflectivity or rainfall (VPR) by following the work presented in Kalogiros et al. (2013b). The method for the detection of the boundaries of the melting layer in each radar ray is based on the well-established characteristic of local minimum of copolar correlation coefficient in the melting layer, with the addition of empirical acceptance criteria for the detections. A scanaverage apparent VPR, which is properly scaled in height from ray to ray to take into account any spatial variations of the characteristics of the melting layer, is estimated and used for the correction.

\section{REFERENCES}

Anagnostou, E. N., and W. F. Krajewski, 1999: Uncertainty quantification of mean-areal radar-rainfall estimates. J. Atmos. Oceanic Technol., 16, 206-215, https://doi.org/10.1175/ 1520-0426(1999)016<0206:UQOMAR>2.0.CO;2.

- M. N. Anagnostou, W. F. Krajewski, A. Kruger, and B. J. Miriovsky, 2004: High-resolution rainfall estimation from X-band polarimetric radar measurements. J. Hydrometeor., 5, 110-128, https://doi.org/10.1175/1525-7541(2004)005<0110: HREFXP $>2.0 . \mathrm{CO} ; 2$.

—, M. Grecu, and M. N. Anagnostou, 2006: X-band polarimetric radar rainfall measurement in Keys area microphysics project. J. Atmos. Sci., 63, 187-203, https://doi.org/10.1175/JAS3592.1.

Anagnostou, M. N., E. N. Anagnostou, and J. Vivekananda, 2006: Correction for rain-path specific and differential attenuation of X-band dual-polarization observations. IEEE Trans. Geosci. Remote Sens., 44, 2470-2480, https://doi.org/10.1109/ TGRS.2006.873204.

,-- , J. Vivekanandan, and F. L. Ogden, 2007: Comparison of raindrop size distribution estimates from X-band and S-band polarimetric observations. IEEE Geosci. Temore Sens. Lett., 4, 601-605, https://doi.org/10.1109/LGRS.2007.903061.

_ , J. Kalogiros, E. N. Anagnostou, and A. Papadopoulos, 2009: Experimental results on rainfall estimation in complex terrain with a mobile X-band polarimetric weather radar. Atmos. Res., 94, 579-595, https://doi.org/10.1016/ j.atmosres.2009.07.009.

,,,--- M. Tarolli, A. Papadopoulos, and M. Borga, 2010: Performance evaluation of high-resolution rainfall estimation by X-band dual-polarization radar for flash flood applications in mountainous basins. J. Hydrol., 394, 4-16, https://doi.org/ 10.1016/j.jhydrol.2010.06.026.

, - _ F. S. Marzano, E. N. Anagnostou, M. Montopoli, and E. Picciotti, 2013: Performance evaluation of a new dualpolarization microphysical algorithm based on long-term $\mathrm{X}$-band radar and disdrometer observations. J. Hydrometeor., 14, 560-576, https://doi.org/10.1175/JHM-D-12-057.1.

- and Coauthors, 2018: Advancing precipitation estimation and streamflow simulations in complex terrain with X-band dualpolarization radar observations. Remote Sens., 10, 1258, https://doi.org/10.3390/rs10081258.

Atlas, D., R. C. Srivastava, and R. S. Sekron, 1973: Early foundations of the measurement of rainfall by radar. Radar in $\mathrm{Me}$ teorology, D. Atlas, Ed., Amer. Meteor. Soc., 86-97, https:// doi.org/10.1007/978-1-935704-15-7_12.

Barros, A. P., and Coauthors, 2014: NASA GPM-Ground Validation Integrated Precipitation and Hydrology Experiment 
2014 Science Plan. Duke University Tech. Rep., 64 pp., https://doi.org/10.7924/G8CC0XMR.

Beard, K. V., and C. Chuang, 1987: A new model for the equilibrium shape of raindrops. J. Atmos. Sci., 44, 1509-1524, https:// doi.org/10.1175/1520-0469(1987)044<1509:

ANMFTE $>2.0 . \mathrm{CO} ; 2$.

Bringi, V. N., and V. Chandrasekar, 2001: Polarimetric Doppler Weather Radar: Principles and Applications. Cambridge University Press, $662 \mathrm{pp}$.

- - J. Hubbert, E. Gorgucci, W. L. Randeu, and M. Schoenhuber, 2003: Raindrop size distribution in different climatic regimes from disdrometer and dual-polarized radar analysis. J. Atmos. Sci., 60, 354-365, https://doi.org/10.1175/ 1520-0469(2003)060<0354:RSDIDC $>2.0 . C O ; 2$.

Brotzge, J., K. Droegemeier, and D. McLaughlin, 2006: Collaborative adaptive sensing of the atmosphere: New radar system for improving analysis and forecasting of surface weather conditions. Transp. Res. Rec., 1948, 144-151, https://doi.org/ 10.1177/0361198106194800116.

Chandrasekar, V., V. N. Bringi, N. Balakrishnan, and D. S. Zrnic, 1990: Error structure of multiparameter radar and surface measurements of rainfall. Part III: Specific differential phase. J. Atmos. Oceanic Technol., 7, 621-629, https://doi.org/ 10.1175/1520-0426(1990)007<0621:ESOMRA>2.0.CO;2.

— A. Hou, E. Smith, V. N. Bringi, S. A. Rutledge, E. Gorgucci, W. A. Petersen, and G. S. Jackson, 2008: Potential role of dual-polarization radar in the validation of satellite precipitation measurements: Rationale and opportunities. Bull. Amer. Meteor. Soc., 89, 1127-1145, https://doi.org/ 10.1175/2008BAMS2177.1.

— Y. Y. Wang, and H. Chen, 2012: The CASA quantitative precipitation estimation system: A five year validation study. Nat. Hazards Earth Syst. Sci., 12, 2811-2820, https://doi.org/ 10.5194/nhess-12-2811-2012.

Chen, H., S. Lim, V. Chandrasekar, and B.-J. Jang, 2017: Urban hydrological application of dual-polarization X-band radar: Case study in Korea. J. Hydrol. Eng., 22, E5016001, https:// doi.org/10.1061/(ASCE)HE.1943-5584.0001421.

Derin, Y., E. N. Anagnostou, M. N. Anagnostou, J. Kalogiros, D. Casella, A. C. Marra, G. Panegrossi, and P. Sano, 2018: Passive microwave rainfall error analysis using high-resolution $\mathrm{X}$-band dual-polarization radar observations in complex terrain. IEEE Trans. Geosci. Remote Sens., 56, 2565-2586, https://doi.org/10.1109/TGRS.2017.2763622.

Frech, M., M. Hagen, and T. Mammen, 2017: Monitoring the absolute calibration of a polarimetric weather radar. J. Atmos. Oceanic Technol., 34, 599-615, https://doi.org/10.1175/ JTECH-D-16-0076.1.

Gorgucci, E., V. Chandrasekar, and L. Baldini, 2006: Correction of $\mathrm{X}$-band radar observation for propagation effects based on the self-consistency principle. J. Atmos. Oceanic Technol., 23, 1668-1681, https://doi.org/10.1175/JTECH1950.1.

Houze R. A., Jr., and Coauthors, 2017: The Olympic Mountains Experiment (OLYMPEX). Bull. Amer. Meteor. Soc., 98, 2167-2188, https://doi.org/10.1175/BAMS-D-16-0182.1.

Houze, R. A., Jr., J. Wurman, S. Brodzik, and A. Frambach, 2018: GPM Ground Validation Doppler on Wheels (DOW) OLYMPEX V2. NASA EOSDIS Global Hydrology Resource Center Distributed Active Archive Center, accessed 20 January 2019, https://doi.org/10.5067/GPMGV/OLYMPEX/ DOW/DATA201.

Huffman, G., R. F. Adler, D. T. Bolvin, G. Gu, E. J. Nelkin, K. P. Bowman, Y. Hong, and E. F. Stocker, 2007: The TRMM
Multisatellite Precipitation Analysis (TMPA): Quasi-global, multiyear, combined-sensor precipitation estimates at fine scales. J. Hydrometeor., 8, 38-55, https://doi.org/10.1175/JHM560.1.

,,,---- , and — 2010: The TRMM Multi-satellite Precipitation Analysis (TMPA). Satellite Rainfall Applications for Surface Hydrology, M. Gebremichael and F. Hossain, Eds., Springer, 3-22.

Illingworth, A. J., and T. M. Blackman, 2002: The need to represent raindrop size spectra as normalized gamma distributions for the interpretation of polarization radar observations. J. Appl. Meteor., 41, 286-297, https://doi.org/10.1175/1520-0450(2002) 041<0286:TNTRRS $>2.0$.CO;2.

Joyce, J. R., E. J. Janowiak, P. A. Arkin, and P. Xie, 2004: CMORPH: A method that produces global precipitation estimates from passive microwave and infrared data at high spatial and temporal resolution. J. Hydrometeor., 5, 487-503, https://doi.org/10.1175/1525-7541(2004)005<0487:CAMTPG> 2.0.CO;2.

Kalogiros, J., M. N. Anagnostou, E. N. Anagnostou, M. Montopoli, E. Picciotti, and F. S. Marzano, 2013a: Optimum estimation of rain microphysical parameters using X-band dual-polarization radar observables. IEEE Trans. Geosci. Remote Sens., 51, 3063-3076, https://doi.org/10.1109/TGRS.2012.2211606.

$\longrightarrow,-$, and,$- \quad 2013 \mathrm{~b}$ : Correction of polarimetric radar reflectivity measurement and rainfall estimates for apparent vertical profile in stratiform rain. J. Appl. Meteor. Climatol., 52, 1170-1186, https://doi.org/10.1175/ JAMC-D-12-0140.1.

,,,,----- , and,- 2014 : Evaluation of a new polarimetric algorithm for rain-path attenuation correction of $\mathrm{X}$-band radar observations against disdrometer. IEEE Trans. Geosci. Remote Sens., 52, 1369-1380, https://doi.org/10.1109/ TGRS.2013.2250979.

Kim, D.-S., and M. Maki, 2012: Validation of composite polarimetric parameters and rainfall rates from an X-band dualpolarization radar network in the Tokyo metropolitan area. Hydrol. Res. Lett., 6, 76-81, https://doi.org/10.3178/hrl.6.76.

,-- , and D. Lee, 2008: Correction of X-band radar reflectivity and differential reflectivity for rain attenuation using differential phase. J. Atmos. Res., 90, 1-9, https://doi.org/ 10.1016/j.atmosres.2008.03.001.

,,,--- 2010 : Retrieval of three-dimensional raindrop size distribution using X-band polarimetric radar data. J. Atmos. Oceanic Technol., 27, 1265-1285, https://doi.org/ 10.1175/2010JTECHA1407.1.

Koffi, A. K., M. Gosset, E.-P. Zahiri, A. D. Ochou, M. Kacou, F. Cazenave, and P. Assamoi, 2014: Evaluation of X-band polarimetric radar estimation of rainfall and rain drop size distribution parameters in West Africa. Atmos. Res., 143, 438461, https://doi.org/10.1016/j.atmosres.2014.03.009.

Kubota, T., and Coauthors, 2007: Global precipitation map using satellite-borne microwave radiometers by the GSMaP project: Production and validation. IEEE Trans. Geosci. Remote Sens., 45, 2259-2275, https://doi.org/10.1109/TGRS.2007.895337.

Lim, S., R. Cifelli, V. Chandrasekar, and S. Y. Matrosov, 2013: Precipitation classification and quantification using X-band dual-polarization weather radar: Application in the hydrometeorology testbed. J. Atmos. Oceanic Technol., 30, 21082120, https://doi.org/10.1175/JTECH-D-12-00123.1.

Maki, M., and Coauthors, 2010: X-band polarimetric radar networks in urban areas. Proc. Sixth European Conf. on Radar in Meteorology and Hydrology, Sibiu, Romania, Administria Nationala de Meteorologie, 202-206. 
Matrosov, S. Y., R. A. Kropfli, R. F. Reinking, and B. E. Martner, 1999: Prospects for measuring rainfall using propagation differential phase in X- and Ka-radar bands. J. Appl. Meteor., 38, 766-776, https://doi.org/10.1175/1520-0450(1999)038<0766: PFMRUP $>2.0 . \mathrm{CO} ; 2$.

—, K. A. Clark, B. E. Martner, and A. Tokay, 2002: C-band polarimetric radar measurements of rainfall. J. Appl. Meteor., 41, 941-952, https://doi.org/10.1175/1520-0450(2002)041<0941: XBPRMO $>2.0 . \mathrm{CO} ; 2$.

—, D. E. Kingsmill, B. E. Martner, and F. M. Ralph, 2005: The utility of X-band radar for quantitative estimates of rainfall parameters. J. Hydrometeor., 6, 248-262, https://doi.org/ 10.1175/JHM424.1.

, R. Cifelli, P. C. Kennedy, S. W. Nesbit, S. A. Rutledge, V. N. Bringi, and B. E. Martner, 2006: A comparative study of rainfall retrievals based on specific differential phase shifts at C- and S-band radar frequencies. J. Atmos. Oceanic Technol., 23, 952-963, https://doi.org/10.1175/JTECH1887.1.

,$- \ldots$, and D. Gochis, 2013: Measurements of heavy convective rainfall in the presence of hail in flood-prone areas using an X-band polarimetric radar. J. Appl. Meteor. Climatol., 52, 395-407, https://doi.org/10.1175/JAMC-D-12-052.1.

McLaughlin, D., D. Pepyne, B. Philips, J. Kurose, M. Zink, D. Westbrook, and P. Kollias, 2009: Shirt-wavelength technology and potential for distributed networks of small radar systems. Bull. Amer. Meteor. Soc., 90, 1797-1817, https:// doi.org/10.1175/2009BAMS2507.1.

Mishra, K. V., and Coauthors, 2016: Deployment and performance analyses of high-resolution Iowa XPOL radar system during the NASA IFloodS campaign. J. Hydrometeor., 17, 455-479, https://doi.org/10.1175/JHM-D-15-0029.1.

Park, S.-G., V. N. Bringi, V. Chandrasekar, M. Maki, and K. Iwanami, 2005a: Correction of radar reflectivity and differential reflectivity for rain attenuation at X-band. Part I: Theoretical and empirical basis. J. Atmos. Oceanic Technol., 22, 1621-1632, https://doi.org/10.1175/JTECH1803.1.

_- M. Maki, K. Iwanami, V. N. Bringi, and V. Chandrasekar, 2005b: Correction of radar reflectivity and differential reflectivity for rain attenuation at X-band. Part II: Evaluation and application. J. Atmos. Oceanic Technol., 22, 1633-1655, https://doi.org/10.1175/JTECH1804.1.

Petersen, W. and P. Gatlin, 2017: GPM Ground Validation Micro Rain Radar (MRR) OLYMPEX. NASA EOSDIS Global Hydrology Resource Center Distributed Active Archive Center, accessed 20 January 2019, https://doi.org/10.5067/GPMGV/ OLYMPEX/MRR/DATA201.

— D. B. Wolff, J. Wang, and A. Tokay, 2017a: GPM Ground Validation Met One Rain Gauge Pairs OLYMPEX. NASA EOSDIS Global Hydrology Resource Center Distributed Active
Archive Center, accessed 20 January 2019, https://doi.org/ 10.5067/GPMGV/OLYMPEX/GAUGES/DATA201.

—, A. Tokay, P. N. Gatlin and M. T. Wingo, 2017b: GPM Ground Validation Autonomous Parsivel Unit (APU) OLYMPEX. NASA EOSDIS Global Hydrology Resource Center Distributed Active Archive Center, accessed 20 January 2019, https://doi.org/10.5067/GPMGV/OLYMPEX/ APU/DATA301.

- - R. Houze, and L. McCurdie, 2018: GPM Ground Validation OLYMPEX Field Campaign Data Collection. Subset used: DOW. NASA EOSDIS Global Hydrology Resource Center Distributed Active Archive Center, accessed 20 January 2019, https://doi.org/10.5067/GPMGV/OLYMPEX/ DATA101.

Shi, Z., H. Chen, V. Chandrasekar, and J. He, 2018: Deployment and performance of an X-band dual-polarization radar during the Southern China monsoon rainfall experiment. Atmosphere, 9, 4, https://doi.org/10.3390/atmos9010004.

Testud, J., E. Le Bouar, E. Obligis, M. Ali-Mehenni, 2000: The rain profiling algorithm applied to polarimetric weather radar. J. Atmos. Oceanic Technol., 17, 332-356, https://doi.org/ 10.1175/1520-0426(2000)017<0332:TRPAAT>2.0.CO;2.

_ J. Lavabre, S. Diss, P. Tabary, and G. Scialom, 2007: HYDRIX radar in FRAMEA - Evaluation of an $\mathrm{X}$ band polarimetric radar using a quasi-co located $\mathrm{S}$ band radar and a raingauge network. Proc. Int. Symp. on X Band Weather Radar Network, Tsukuba, Japan, National Research Institute for Earth Science and Disaster Prevention, 7-10, http://www.novimet.com/ download/Testud\%20et\%20al_Japan_2007.pdf.

Thurai, M., K. V. Mishra, V. N. Bringi, and W. F. Krajewski, 2017: Initial results of a new composite-weighted algorithm for dualpolarized X-band rainfall estimation. J. Hydrometeor., 18, 1081-1100, https://doi.org/10.1175/JHM-D-16-0196.1.

Ushio, T., and Coauthors, 2009: A Kalman filter approach to the Global Satellite Mapping of Precipitation (GSMaP) from combined passive microwave and infrared radiometric data. J. Meteor. Soc. Japan, 87A, 137-151, https://doi.org/10.2151/jmsj.87A.137.

Wang, Y., and V. Chandrasekar, 2010: Quantitative precipitation estimation in the CASA X-band dual-polarization radar network. J. Atmos. Oceanic Technol., 27, 1665-1676, https:// doi.org/10.1175/2010JTECHA1419.1.

Yoshikawa, E., and Coauthors, 2010: Development and initial observation of high-resolution volume-scanning radar for meteorological application. IEEE Trans. Geosci. Remote Sens., 48, 3225-3235, https://doi.org/10.1109/TGRS.2010.2045762.

Yu, N., N. Gaussiat, and P. Tabary, 2018: Polarimetric X-band weather radars for quantitative precipitation estimation in mountainous regions. Quart. J. Roy. Meteor. Soc., 144, 2603 2619, https://doi.org/10.1002/qj.3366. 